\title{
A general modeling framework for the operational planning of petroleum supply chains
}

\author{
Sérgio M.S. Neiro ${ }^{\mathrm{a}, 1}$, José M. Pinto ${ }^{\mathrm{a}, \mathrm{b}, *, 2}$ \\ a Department of Chemical Engineering, University of São Paulo, 05508-900 São Paulo, SP, Brazil \\ ${ }^{\mathrm{b}}$ Department of Chemical Engineering and Chemistry, Polytechnic University, Brooklyn, NY 11201, USA
}

\begin{abstract}
In the literature, optimization models deal with planning and scheduling of several subsystems of the petroleum supply chain such as oilfield infrastructure, crude oil supply, refinery operations and product transportation. The focus of the present work is to propose a general framework for modeling petroleum supply chains. As a starting point, processing units are modeled based on the framework developed by Pinto et al. [Computers and Chemical Engineering 24 (2000) 2259]. Particular frameworks are then proposed to storage tanks and pipelines. Nodes of the chain are considered as grouped elementary entities that are interconnected by intermediate streams. The complex topology is then built by connecting the nodes representing refineries, terminals and pipeline networks. Decision variables include stream flow rates, properties, operational variables, inventory and facilities assignment. The resulting multiperiod model is a large-scale MINLP. The proposed model is applied to a real-world corporation and results show model performance by analyzing different scenarios.
\end{abstract}

(c) 2003 Elsevier Ltd. All rights reserved.

Keywords: Petroleum complex; Supply chain management; Mixed-integer optimization

\section{Introduction}

Companies have been forced to overstep their physical frontiers and to visualize the surrounding business environment before planning their activities. Range vision should cover all members that participate direct or indirectly in the work to satisfy a customer necessity. Coordination of this virtual corporation may result in benefits for all members of the chain individually. Beamon (1998) defines such virtual corporation as an integrated process wherein a number of business entities (suppliers, manufacturers, distributors and retailers) work together in an effort to acquire raw materials, convert them into specified final products and deliver these final products to retailers. Under another point of view, Tan (2001) states that there is a definition of supply chain management (SCM), which emerges from transportation and logistics literature of the wholesaling and retailing industry that emphasizes the importance of physical distribution and integrated logistics. According to Lamming (1996), this

\footnotetext{
* Corresponding author. Tel.: +1-718-260-3569; fax: +1-718-260-3125.

E-mail address: jpinto@poly.edu (J.M. Pinto).

1 Tel.: +55-11-3091-2237; fax: +55-11-3813-2380

2 Tel.: +1-718-260-3569; fax: +1-718-260-3125.
}

is probably where the term supply chain management was originally used.

According to Thomas and Griffin (1996), current research in the area of SCM can be classified in three categories: Buyer-Vendor, production-distribution and inventory-distribution coordination. The authors present an extensive literature review for each category. Vidal and Goetschalckx (1997) present a review of mixed integer problems (MIP) that focuses on the identification of the relevant factors included in formulations of the chain or its subsystems and also highlights solution methodologies.

Bok, Grossmann, and Park (2000) present an application to the optimization of continuous flexible process networks. Modeling considers intermittent deliveries, production shortfalls, delivery delays, inventory profiles and job changeovers. A bi-level solution methodology is proposed to reduce computational expense. Zhuo, Cheng, and Hua (2000) introduce a supply chain model that involves conflicting decisions in the objective function. Goal programming is used to solve the multi-objective optimization problem. Perea, Grossmann, Ydstie, and Tahmassebi (2000) and Perea-López, Grossmann, and Ydstie (2001) present an approach that is capable of capturing the dynamic behavior of the supply chain by modeling flow of materials and information within the supply chain. Information is considered 


\begin{tabular}{|ll} 
Nomenclature \\
Indices: & \\
$p$ & property \\
$s$ & stream \\
$t$ & time period \\
$u, u^{\prime}$ & unit \\
$v$ & operating variable \\
Sets: & \\
$\mathbf{P I}_{u}$ & properties of the inlet stream of unit $u$ \\
$\mathbf{P O}$ & properties of outlet stream $s$ of unit $u$ \\
$\mathbf{S} \mathbf{O}_{u}$ & outlet streams of unit $u$ \\
$\mathbf{T}$ & time periods $\{t \mid t=1, \ldots, N T\}$ \\
$\mathbf{U}_{\text {co }}$ & product tanks at refinery sites dedicated to \\
& supply local market \\
$\mathbf{U}_{\text {dem }}$ & product tanks that present direct demand \\
& from a consumer \\
$\mathbf{U}_{f}$ & petroleum tanks \\
$\mathbf{U}_{u}$ & units whose outlet streams feed unit $u$ \\
$\mathbf{U}_{\text {nc }}$ & product tanks at refinery sites that \\
& supply local and other markets \\
$\mathbf{U O}_{u, s}$ & units that are fed by stream $s$ of unit $u$ \\
$\mathbf{U}_{p}$ & product tanks \\
$\mathbf{U}_{\text {pipe }}$ & units that represent pipelines \\
$\mathbf{U}_{\text {port }}$ & petroleum tanks that store the crude \\
& oil from suppliers \\
$\mathbf{U}_{\text {pu }}$ & processing units at refinery sites \\
$\mathbf{U}_{r}$ & product tanks at refineries \\
$\mathbf{U S}_{u}$ & ordered pairs unit/stream $\left(u^{\prime}, s\right)$ that \\
& feeds unit $u$ \\
$\mathbf{U}_{\text {tank }}$ & all storage tanks of the supply chain \\
$\mathbf{V O} \mathbf{O}_{u}$ & operating variables of unit $u$ \\
& a
\end{tabular}

\section{Parameters:}

$\operatorname{Cinv}_{u, t} \quad$ inventory cost of tank $u$ at time period $t$

Cpet $_{u, t} \quad$ price of petroleum $u\left(u \in \mathbf{U}_{\text {port }}\right)$ at

$\begin{array}{ll} & \text { time period } t \\ \mathrm{Cp}_{u, t} & \text { sale price of product } u\left(u \in \mathbf{U}_{p}\right)\end{array}$

at time period $t$

$\mathrm{Cr}_{u} \quad$ fixed operating cost coefficient of unit $u$

$\mathrm{Ct}_{u} \quad$ transportation cost for pipeline $u$

$\mathrm{Cv}_{u, v} \quad$ variable coefficient cost of

the operating variable $v$ of unit $u$

$\operatorname{Dem}_{u, t} \quad$ demand of product $u$ at time period

$\begin{array}{ll}\mathrm{PF}_{u, p, t}^{\mathrm{L}} & t\left(u \in \mathbf{U}_{p}\right) \\ & \text { lower bound of inlet property } p \text { of unit } u\end{array}$ at time period $t$

$\mathrm{PF}_{u, p, t}^{\mathrm{U}} \quad$ upper bound of inlet property $p$ of unit $u$ at time period $t$

$\operatorname{Prop}_{u, s, p} \quad$ standard property value $p$ of the outlet stream $s$ from unit $u$

$\mathrm{QF}_{u}^{\mathrm{L}} \quad$ lower bound for feed flow rate of unit $u$

$\mathrm{QF}_{u}^{\mathrm{U}} \quad$ upper bound for feed flow rate of unit $u$
QGain $_{u, s, v} \quad$ flow rate gain of outlet stream $s$ of unit $u$ due to operating variable $u$

$\mathrm{QS}_{u}^{\mathrm{L}} \quad$ lower bound for outlet flow rate of unit $u$

$\mathrm{QS}_{u}^{\mathrm{U}} \quad$ upper bound for outlet flow rate of unit $u$

$V_{u, v}^{\mathrm{L}} \quad$ lower bound for operating variable $v$ of

$V_{u, v}^{\mathrm{U}}$ unit $u$

upper bound for operating variable $v$ of unit $u$

Variables

$I_{u, s, p, t}$

mixture indices of property $p$ of

stream $s$ of unit $u$ at time period $t$

$\mathrm{PF}_{u, p, t} \quad$ property $p$ of the feed stream at unit $u$ at time period $t$

$\mathrm{PS}_{u, s, p, t} \quad$ property $p$ of the outlet stream $s$ at unit $u$ at time period $t$

$\mathrm{QF}_{u, t} \quad$ feed flow rate of unit $u$ at time period $t$

$\mathrm{QS}_{u, s, t} \quad$ outlet flow rate of stream $s$ at unit $u$ at time period $t$

$Q_{u^{\prime}, s, u, t} \quad$ flow rate of stream $s$ between units $u^{\prime}$ and $u$ at time period $t$

$\operatorname{Vol}_{u, t} \quad$ inventory level of tank $u$ at time period $t$

$V_{u, v, t} \quad$ operating variable $v$ of unit $u$ at time period $t$

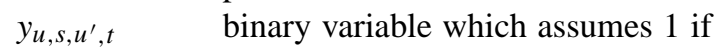
tank $u$ is chosen to supply $u^{\prime}$ with $s$ at time period $t ; 0$ otherwise

Processing unit:

$\begin{array}{ll}\text { CD } i & \text { atmospheric distillation column } i \\ \text { DEPROP } & \text { C3/C4 separation unit } \\ \text { FCC } i & \text { fluid catalytic cracking unit } i \\ \text { HT } i & \text { hydrotreatment unit } i \\ \text { PDA } & \text { propane-deasphalting unit } \\ \text { SOLV } i & \text { solvent distillation column } i \\ \text { UC } i & \text { bun unit } i \\ \text { UFN } & \text { naphtha fraction unit } \\ \text { UMTBE } & \text { unit for MTBE production } \\ \text { URA } & \text { aromatic reform unit } \\ \text { URC } & \text { catalytic reform unit } \\ \text { UVGA } & \text { alcoholization unit } \\ \text { VD } i & \text { vacuum distillation column } i\end{array}$

\section{Product tank:}

PBEN pool of benzene

PC3 pool of $\mathrm{C} 3$

PC4 pool of $\mathrm{C} 4$

PDIL pool of kerosene for dilution

PDILT pool of dye diluent

PDIN pool of regular diesel

PDMA pool of maritime diesel

PDME pool of metropolitan diesel

PDO pool of decanted oil 


\begin{tabular}{|ll|}
\hline PEXFO & pool of fuel oil (exportation type) \\
PFO1A & pool of fuel oil (type 1A) \\
PFO1B & pool of fuel oil (type 1B) \\
PFO4A & pool of fuel oil (type 4A) \\
PGC & pool of fuel gas \\
PGLA & pool of jet gasoline \\
PGLE & pool of exportation gasoline \\
PGLN & pool of gasoline \\
PGLP & pool of LPG \\
PJFUEL & pool of jet fuel \\
PLCO & pool of light fuel oil \\
PMTBE & pool of MTBE \\
PMTU & pool of mineral terpentine \\
PNAL & pool of light naphtha \\
PNAP & pool of naphtha \\
PNAT & pool of treated naphtha \\
POC & pool of fuel oil \\
POCBV & pool of BV fuel oil \\
POCP & pool of premium fuel oil \\
PPGC & pool of petroleum green bun \\
PPQN & pool of petrochemical naphtha \\
PRAT & pool of ATR \\
PSOLB & pool of rubber solvent \\
PTOL & pool of toluene \\
PXIL & pool of xylene \\
& \\
Stream: & \\
ASFR & asphalt residue \\
ATR & atmospheric residue \\
BEN & benzene \\
C3 & propane \\
C3C4 & C3/C4 mixture \\
C4 & butane \\
CN & bun naphtha \\
CRAN & cracked naphtha \\
DAO & deasphalted oil \\
DILT & dye diluent \\
DIN & regular diesel \\
DMA & maritime diesel \\
DME & metropolitan diesel \\
DO & decanted oil from FCC \\
FDSOL1 & bottom solvent from SOLV1 \\
FDSOL2 & bottom solvent from SOLV2 \\
GC & fuel gas \\
GLN & gasoline \\
HD & heavy diesel \\
HGO & bun heavy gas oil \\
HK & hydrotreated kerosene \\
HN & heavy naphtha \\
HNU & heavy naphtha from UFN \\
HTD & hydrotreated diesel \\
HTOL & heavy toluene \\
JFUEL & jet fuel \\
K & kerosene \\
\hline
\end{tabular}

\begin{tabular}{|ll|}
\hline LALC & light alcohol \\
LCO & light fuel oil \\
LD & light diesel \\
LGO & bun light gas oil \\
LN & light naphtha \\
LNU & light naphtha from UFN \\
MTBE & methyl terc butyl ether \\
OC & fuel oil \\
PGC & petroleum green bun \\
RAF & rafinate \\
RFOR & reform \\
RNU & naphtha for reform from UFN \\
SOLB & rubber solvent \\
TOL & toluene \\
TPSOL1 & top solvent from SOLV1 \\
TPSOL2 & top solvent from SOLV2 \\
VGO & gas oil mixture \\
VR & vacuum residue \\
XIL & xylene \\
\hline
\end{tabular}

as perturbation of a system control whereas material flows are considered to be control variables. Therefore, this approach is able to react on time and to coordinate the whole supply chain for changing demand conditions. Similarly, Ydstie, Coffey, and Read (2003) apply concepts from dynamics and control in the management of highly distributed supply chains. Important aspects of the supply chain problem are captured in a graph representation, such as topology, transportation, shipping/receiving and market conditions, assembly/disassembly, storage of assets, forecasting and performance evaluation. Song, Bok, Park, and Park (2002) present a design problem of multiproduct, multi-echelon supply chain. Transportation cost is treated as a continuous piecewise linear function of the distance and a discontinuous piecewise linear function of the transportation volume, whereas installation costs are expressed as a function of the capacity. Feord, Jakeman, and Shah (2002) propose a network model whose main objective is to decide which orders should be met, delayed or not to be delivered.

The petroleum industry can be characterized as a typical supply chain. All levels of decisions arise in such a supply chain, namely, strategic, tactical and operational. In spite of the complexity involved in the decision making process at each level, much of their management is still based on heuristics or on simple linear models. According to Forrest and Oettli (2003), most of the oil industry still operates its planning, central engineering, upstream operations, refining, and supply and transportation groups as complete separate entities. Therefore, systematic methods for efficiently managing the petroleum supply chain must be exploited. In the next section, the petroleum supply chain scope is described as well as recent developments found in the literature concerning its subsystems. 


\section{Petroleum supply chain}

The petroleum supply chain is illustrated in Fig. 1. Petroleum exploration is at the highest level of the chain. Decisions regarding petroleum exploration include design and planning of oil field infrastructure. Petroleum may be also supplied from international sources. Oil tankers transport petroleum to oil terminals, which are connected to refineries through a pipeline network. Decisions at this level incorporate transportation modes and supply planning and scheduling. Crude oil is converted to products at refineries, which can be connected to each other in order to take advantage of each refinery design within the complex. Products generated at the refineries are then sent to distribution centers. Crude oil and products up to this level are often transported through pipelines. From this level on, products can be transported either through pipelines or trucks, depending on consumer demands. In some cases, products are also transported through vessels or by train.

In general, production planning includes decisions such as individual production levels for each product as well as operating conditions for each refinery in the network, whereas product transportation focuses on scheduling and inventory management of the distribution network.

Products at the last level presented in Fig. 1 are actually raw materials for a variety of processes. This fact indicates that the petroleum supply chain could be further extended. However, this work deals with the petroleum supply chain as depicted in Fig. 1.

Sear (1993) was probably the first to address the supply chain management in the context of an oil company. The author developed a linear programming network model for planning the logistics of a downstream oil company. The model involves crude oil purchase and transportation, processing of products and transportation, and depot operation. Escudero, Quintana, and Salmeron (1999) proposed an LP model that handles the supply, transformation and distribution of an oil company that accounts for uncertainties in supply costs, demands and product prices. Dempster, Pedron, Medova, Scott, and Sembos (2000) applied a stochastic programming approach to planning problems for a consortium of oil companies. First, a deterministic multiperiod linear programming model is developed for supply, production and distribution. The deterministic model is then used as a basis for implementing a stochastic programming formulation with uncertainty in product demands and spot supply costs. More recently, Lasschuit and Thijssen (2003) point out how the petrochemical supply chain is organized and stress important issues that must be taken into account when formulating a model for the oil and chemical industry.

Important developments of subsystems of the petroleum supply chain can be found in literature. Iyer, Grossmann, Vasantharajan, and Cullick (1998) developed a multiperiod MILP for planning and scheduling of offshore oil field infrastructure investments and operations. The nonlinear reservoir behavior is handled with piecewise linear approximation functions. A sequential decomposition technique is applied. Van den Heever and Grossmann (2000) presented a nonlinear model for oilfield infrastructure that involves design and planning decisions. The authors consider non-linear reservoir behavior. A logic-based model is proposed that is solved with a bilevel decomposition technique. This technique aggregates time periods for the design problem and subsequently disaggregates them for the planning sub-problem. Van den Heever, Grossmann, Vasantharaan, and Edwards (2000) addressed the design and planning of offshore oilfield infrastructure focusing on business rules. A disjunctive model capable to deal with the increased order of magnitude due to the business rules is proposed. Ierapetritou, Floudas, Vasantharaan, and Cullick (1999) studied the optimal location of vertical wells for a given reservoir property map. The problem is formulated as a large scale MILP and solved by a decomposition technique that relies on quality cut constraints. Kosmidis, Perkins, and Pistikopoulos (2002) described an MILP formulation for the well allocation and operation of integrated gas-oil systems

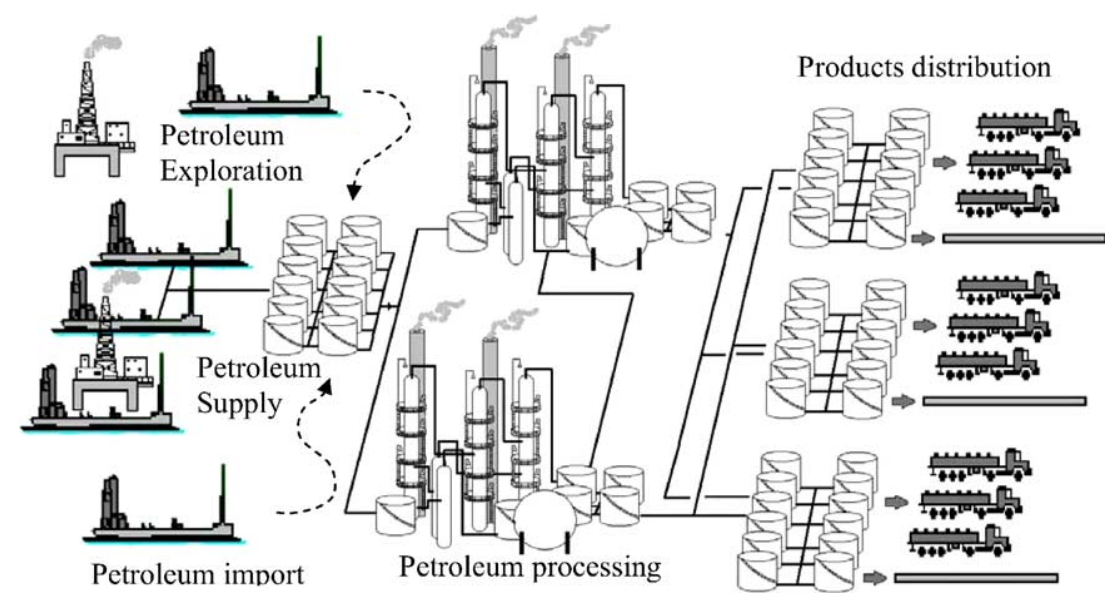

Fig. 1. General petroleum supply chain (PSC). 
whereas Barnes, Linke, and Kokossis (2002) focused on the production design of offshore platforms.

Cheng and Duran (2003) focused on the crude oil worldwide transportation based on the statement that this element of the petroleum supply chain is the central logistics that links the upstream and downstream functions, playing a crucial role in the global supply chain management in the oil industry.

At another level of the supply chain, Lee, Pinto, Grossmann, and Park (1996) concentrated on the short-term scheduling of crude oil supply for a single refinery. Más and Pinto (2003) and Magalhães and Shah (2003) focus on the crude oil supply scheduling. The former developed a detailed MILP formulation comprised of tankers, piers, storage tanks, substations and refineries, whereas the latter addresses a scheduling problem composed of a terminal, a pipeline, a refinery crude storage area and its crude units. Pinto, Joly, and Moro (2000) and Pinto and Moro (2000) focused on the refinery operations. The former work focuses on production scheduling for several specific areas in a refinery such as crude oil, fuel oil, asphalt and LPG whereas the latter addresses a nonlinear production planning. Jia and Ierapetritou (2003) concentrate on the short-term scheduling of refinery operations. Crude oil unloading and blending, production unit operations and product blending and delivery are first solved as independent problems. Each sub-system is modeled based on a continuous time formulation. Integration of the three sub-systems is then accomplished by applying heuristic based Lagrangean decomposition. Wenkai and Hui (2003) studied similar problem to that addressed by Jia and Ierapetritou (2003) and propose a new modeling technique and solution strategy to schedule crude oil unloading and storage. At the refinery level, units such as crude distillation unit and fluidized-bed catalytic cracking were modeled and a new analytical method was proposed to provide additional information for intermediate streams inside the refinery.

Ponnambalam, Vannelli, and Woo (1992) developed an approach that combines the simplex method for linear programming with an interior point method for solving a multiperiod planning model in the oil refinery industry. Still at the production planning level, Liu and Sahinidis (1997) presented a fuzzy programming approach for solving a petrochemical complex problem involving uncertainty in model parameters. Bok, Lee, and Park (1998) addressed the problem of long-range capacity expansion planning for a petrochemical industry.

Ross (2000) formulated a planning supply network model on the petroleum distribution downstream segment. Resource allocation such as distribution centers (new and existing) and vehicles is managed in order to maximize profit. Delivery cost is determined depending on the geographic zone, trip cost, order frequency and travel distance for each customer. Iakovou (2001) proposed a model that focuses on the maritime transportation of petroleum products considering a set of transport modalities. One of the main objectives of this work was to take into account the risks of oil spill incidents. Magatão, Arruda, and Neves (2002) propose an MILP approach to aid the decision-making process for schedule commodities on pipeline systems. On the product storage level, Stebel, Arruda, Fabro, and Rodrigues (2002) present a model involving the decision making process on storage operations of liquefied petroleum gas (LPG).

As a major conclusion of the previous paragraphs, only subsystems of the petroleum supply chain have been studied at a reasonable level of detail. The reason is the resulting complexity when parts of the chain are put together within the same model. Nevertheless, logic-based approaches have shown potential to efficiently model and solve large systems without reducing problem complexity (Türkay \& Grossmann, 1996; Van den Heever \& Grossmann, 1999; Vecchietti \& Grossmann, 2000). This fact, allied to the development of new powerful computers and changing business necessities provide motivation to increase the scope of petroleum supply chain modeling.

Therefore, the present work develops an integrated model for a petroleum supply chain that can be applied to real-word problems. A set of crude oil suppliers, refineries that can be interconnected by intermediate and final product streams and a set of distribution centers compose the system considered in this work. Distribution through pipelines is defined from petroleum terminals to refineries and from refineries to intermediate terminals or directly to distribution centers.

The paper is organized as follows: the problem statement is given in Section 3, followed by the mathematical models for processing units, storage tanks, pipelines and the optimization model for the entire petroleum supply chain in Section 4. An illustrative example for a simplified refinery is presented in Section 5. Section 6 presents the petroleum supply chain-case study, and the results obtained by applying the proposed modeling framework. Computational results are discussed in Section 7. Finally, conclusions and research needs are discussed in the last section.

\section{Problem statement}

\subsection{General problem}

According to Lasschuit and Thijssen (2003), there is great appeal that the supply chain of oil and chemical industry involve the horizontal integration across departmental divisions and coupled coordination of the layers of strategic, planning, scheduling and operational execution (vertical integration). This whole context is usually described by massive amount of operational data and decision making processes that comprise feedstock, manufacturing, exchange and blending across supply, distribution, terminals and depots, and into demand, channel segmentation. It will be clearly verified, in the next section, that the case study to be addressed in this work clearly points towards the stated requirements. 


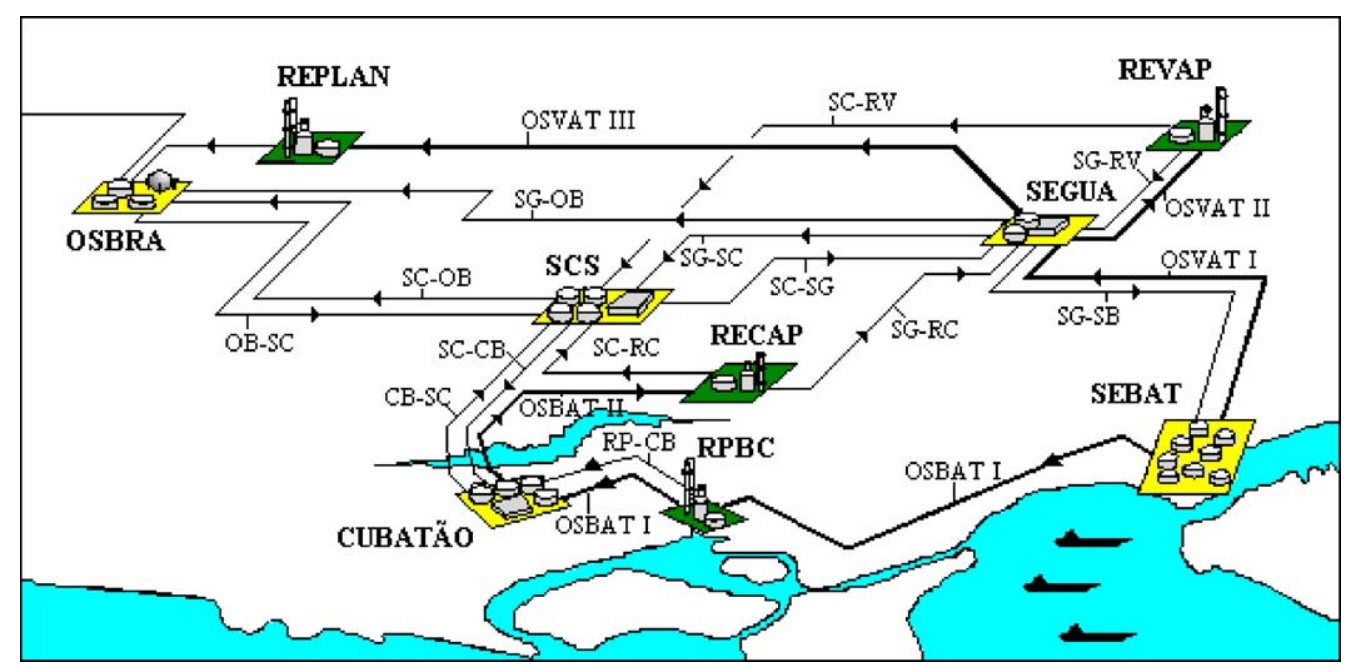

Fig. 2. Supply chain—case study.

\subsection{Case study}

The case study considered in this work partially represents the real-world petroleum supply chain planning problem of Petrobras (Brazil). Petrobras has 59 petroleum exploration sites among which 43 are offshore, 11 refineries that are located along the country's territory and a large number of facilities such as terminals and pipeline networks. Refinery sites are concentrated mainly in southern Brazil where 7 sites are found, 4 of which represent $47 \%$ of the company's processing capacity. These refineries are located in the most important and strategic consumer markets. Therefore, the present work addresses the supply chain comprised of these 4 refineries, namely: REVAP, RPBC, REPLAN and RECAP (Fig. 2). Five terminals compose the storage facilities, namely: SEBAT, SEGUA, CUBATAO, SCS and OSBRA; and a pipeline network for crude oil supply and another for product distribution compose the transportation facilities. The petroleum and product storage and distribution facilities are considered to be organized as detailed in Figs. 3 and 4, respectively. Refineries are supplied with petroleum by two main pipeline branches. The OSVAT segment connects refineries REVAP and REPLAN to the SEBAT terminal, whereas the OSBAT segment connects refineries RPBC and RECAP to the same terminal. Terminals between extreme nodes are required in case intermediate storage is needed or pumping capacity is limited.

Crude oil is acquired from a variety of suppliers and its properties strongly depend on supplier origin, which result in different petroleum types. Twenty petroleum types

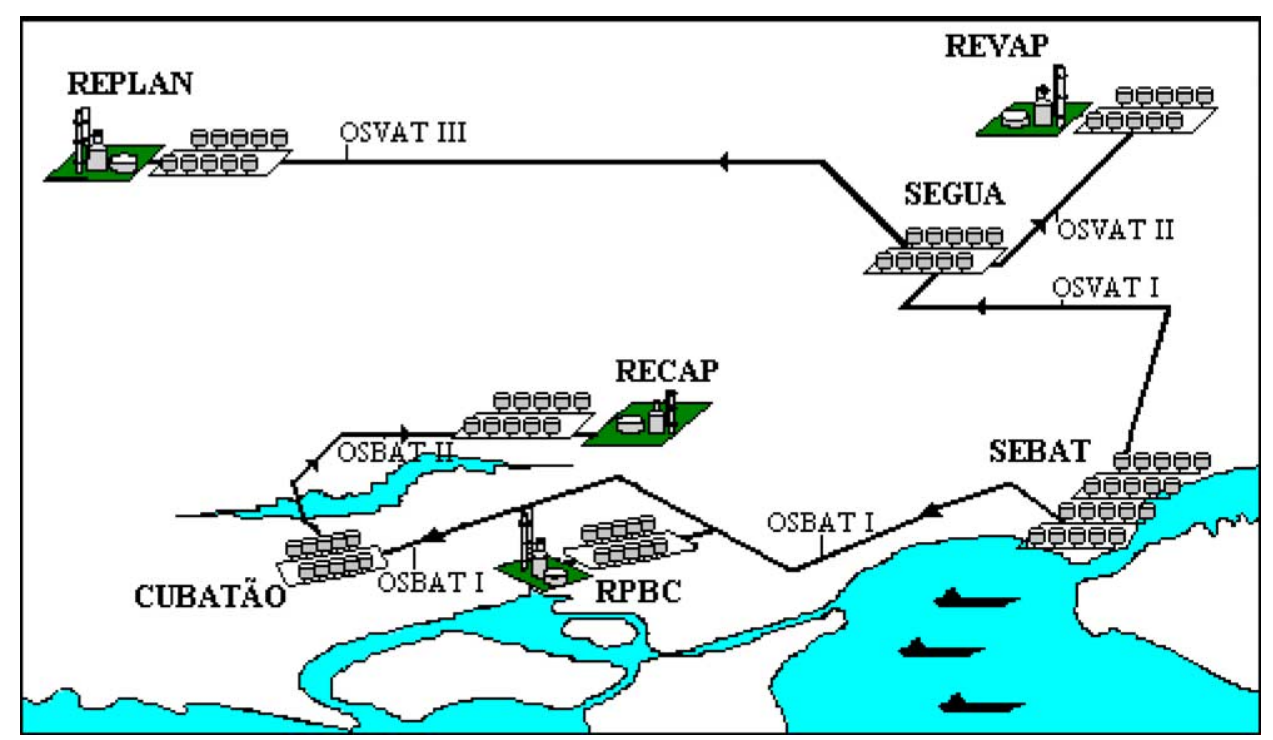

Fig. 3. Crude oil supply—case study. 


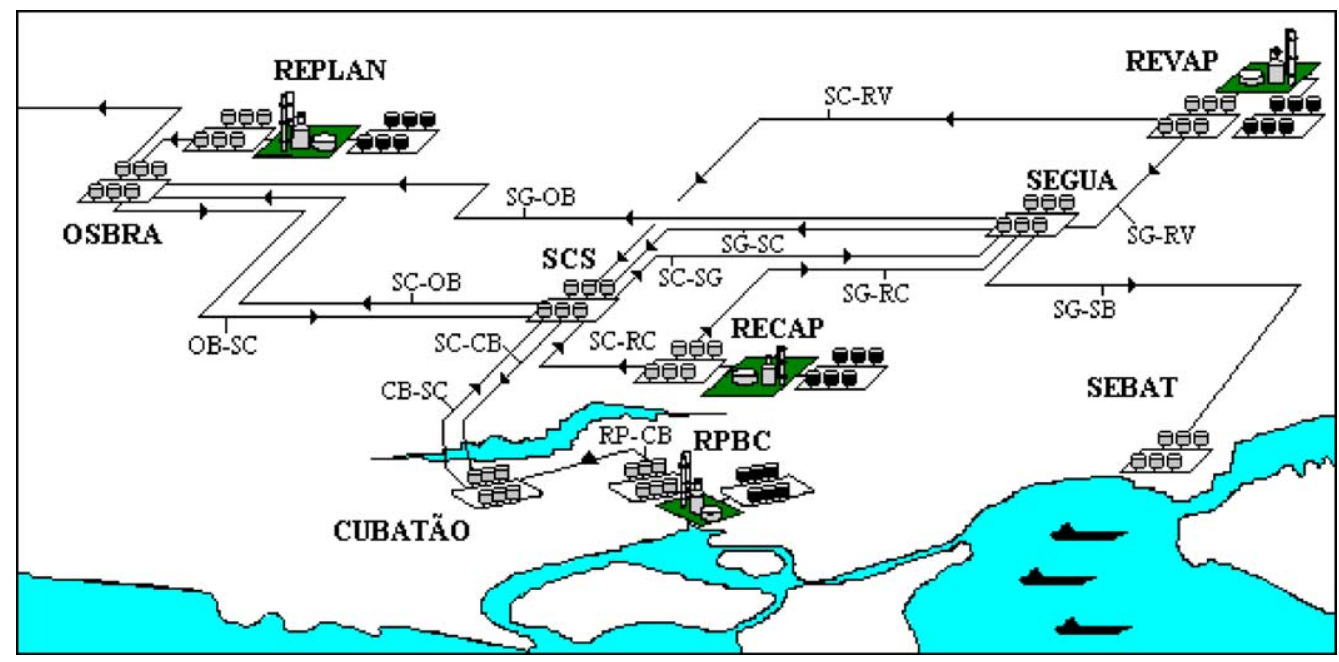

Fig. 4. Products storage and distribution-case study.

are considered to supply the complex. The overall charge is supplied through SEBAT whereby it is then distributed to the terminals and refineries as described in the previous paragraph. Since petroleum types from different suppliers present distinct properties, every petroleum type is stored at an assigned petroleum tank that is also dedicated. Therefore, SEBAT holds twenty petroleum tanks as shown in Fig. 3. Ten oil types are potentially supplied to RECAP and the remaining 10 are potential suppliers to REVAP, RPBC and REPLAN. Refineries and terminals also contain tank farm that store each of the petroleum types, according to Fig. 3.

The whole complex is able to provide 32 products to local markets. Six products may be also transferred to supply the demand from other regions. Transfer is accomplished by either vessels or pipelines. In case the former is selected, products are sent to the SEBAT or CUBATAO terminals, whereby products are shipped. In case of transfer through pipeline, products are sent to the OSBRA terminal, whereby they are pumped. Demands from other regions are imposed at the tanks of the transshipment terminals.

In analogy to petroleum types, different products are also stored at dedicated tanks, so that every refinery and terminal contains a set of storage tanks for products. Fig. 4 presents the two types of product tanks. The black tanks represent products that supply only the local market, whereas the gray tanks represent products that supply either market, local and from other regions.

The problem is then to develop an optimization model for the planning of the above described petroleum supply chain that accounts for multiple time periods. Decisions involve selection of oil types and their transportation plan, production levels respecting quality constraints as well as operating variables of processing units at refineries and product distribution plan and inventory management along the planning horizon.

\section{Mathematical models}

The petroleum supply chain presented in the previous section can be broadly described through three classes of elements that are classified according to their function in the chain. The next three sections present the mathematical model of each element highlighting their particularities and Section 4.4 presents the petroleum supply chain model based on these three classes of elements.

\subsection{Processing unit model}

Processing unit is defined as a piece of equipment that is able to physically or chemically modify the material fed into it. According to this definition, processing units are all those that compose the refinery topology and are modeled based on the general framework developed by Pinto and Moro (2000) for a single refinery, as shown in Fig. 5. Generally, stream $s 1$ from unit $u 1$ is sent to unit $u$ at a flowrate $Q_{u 1, s 1, u, t}$ at time period $t$. The same unit $(u 1)$ can send a variety of its outlet streams to unit $u$ given by the set $\{s 1, s 2, \ldots, s N S 1\}$. The set $\mathbf{U S}_{u}$ contains ordered pairs that represent all streams from every unit that feeds unit $u$. Mixture is always accomplished before feeding. Variable $\mathrm{QF}_{u, t}$ denotes the resulting feed stream flowrate for unit $u$ at time period $t$. Every stream is characterized by a set of properties $\{p 1, p 2, \ldots, p N P\}$. Relevant properties at the inlet and outlet streams are given by the sets $\mathbf{P} \mathbf{I}_{u}$ and $\mathbf{P} \mathbf{O}_{u, s}$, respectively, whereas the variables $\mathrm{PF}_{u, p, t}$ and $\mathrm{PS}_{u, s, p, t}$ denote the property values of the inlet and outlet streams at time period $t$, respectively. The unit feed is converted into a set of products $\mathbf{S O}_{u}=\left\{s^{\prime} 1, s^{\prime} 2, \ldots, s^{\prime} N\right\}$. Variable $\mathrm{QS}_{u, s, t}$ represents the outlet flowrate of every stream $s$ that leaves unit $u$ at time period $t$. Since an outlet stream can be sent to more than one unit $\left(\mathbf{U} \mathbf{O}_{u, s}=\left\{u^{\prime} 1, u^{\prime} 2, \ldots, u^{\prime} N\right\}\right)$ to further processing or storage, there is a splitter assigned to every outlet stream. Different outlet streams may be characterized by specific 


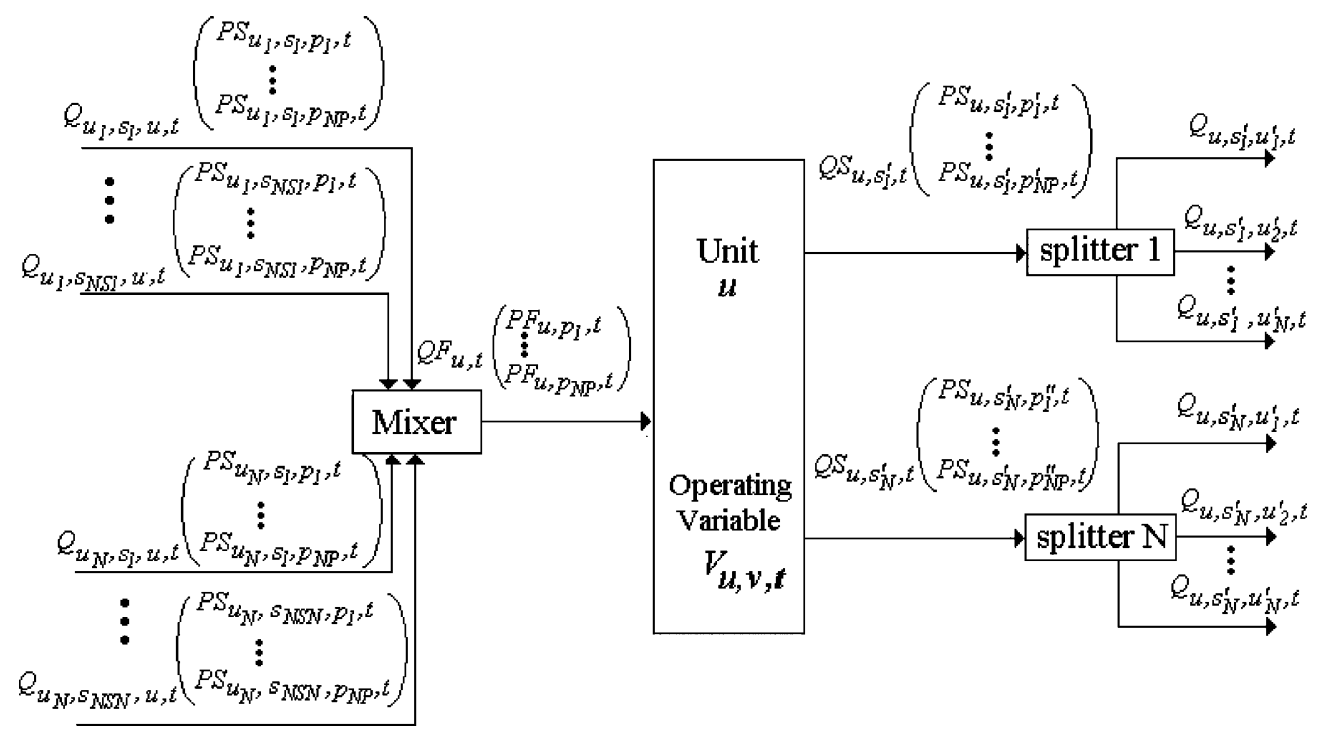

Fig. 5. Model framework for units.

property sets, for instance $\mathbf{P} \mathbf{O}_{u, s^{\prime} 1}=\left\{p^{\prime} 1, \ldots, p^{\prime} N P\right\}$ and $\mathbf{P O}_{u, s^{\prime} N}=\left\{p^{\prime \prime} 1, \ldots, p^{\prime \prime} N P\right\}$. Processing at unit $u$ can be influenced by a set of operating variables $V O_{u}=$ $\{v 1, v 2, \ldots, v N V\}$. Every operating variable corresponds to a decision variable $V_{u, v, t}$. Therefore, based on the variables and sets defined so far and on the framework depicted in Fig. 5, the following equations can be considered to model each processing unit $u \in \mathbf{U}_{\mathrm{pu}}$, where $\mathbf{U}_{\mathrm{pu}}$ is the set of processing units that compose each of the refinery topologies:

$\mathrm{QF}_{u, t}=\sum_{\left(u^{\prime}, s\right) \in \mathbf{U S}_{u}} Q_{u^{\prime}, s, u, t} \quad \forall u \in \mathbf{U}_{\mathrm{pu}}, t \in \mathbf{T}$

$$
\begin{array}{r}
\mathrm{QS}_{u, s, t}=\mathrm{QF}_{u, t} \cdot f_{u, s}\left(\mathrm{PF}_{u, p, t}\right)+\sum_{u \in \mathbf{V O}} \mathrm{QGain}_{u, s, v} \cdot V_{u, v, t} \\
\forall u \in \mathbf{U}_{\mathrm{pu}}, s \in \mathbf{S O}_{u}, p \in \mathbf{P} \mathbf{I}_{u}, t \in \mathbf{T}
\end{array}
$$

$$
\mathrm{QS}_{u, s, t}=\sum_{u^{\prime} \in \mathbf{U} \mathbf{O}_{u, s}} Q_{u, s, u^{\prime}, t} \quad \forall u \in \mathbf{U}_{\mathrm{pu}}, s \in \mathbf{S} \mathbf{O}_{u}, t \in \mathbf{T}
$$

$$
\begin{aligned}
& \mathrm{PF}_{u, p, t}=\frac{\sum_{\left(u^{\prime}, s\right) \in \mathbf{U S}_{u}} Q_{u^{\prime}, s, u, t} \cdot \mathbf{P S}_{u^{\prime}, s, p, t}}{\sum_{\left(u^{\prime}, s\right) \in \mathbf{U S}_{u}} Q_{u^{\prime}, s, u, t}} \\
& \forall u \in \mathbf{U}_{\mathrm{pu}}, p \in \mathbf{P I}_{u}, t \in \mathbf{T}
\end{aligned}
$$

$$
\begin{gathered}
\mathrm{PS}_{u, s, p, t}=f_{u, s, p}\left(\mathrm{QF}_{u, t}, \mathrm{PF}_{u, p, t}\left|p \in \mathbf{P I}_{u}, V_{u, v, t}\right| v \in \mathbf{V O}_{u}\right) \\
\forall u \in \mathbf{U}_{\mathrm{pu}}, s \in \mathbf{S O}_{u}, p \in \mathbf{P} \mathbf{O}_{u, s}, t \in \mathbf{T} \\
\mathrm{QF}_{u}^{\mathrm{L}} \leq \mathrm{QF}_{u, t} \leq \mathrm{QF}_{u}^{\mathrm{U}} \quad \forall u \in \mathbf{U}_{\mathrm{pu}}, t \in \mathbf{T} \\
V_{u, v}^{\mathrm{L}} \leq V_{u, v, t} \leq V_{u, v}^{\mathrm{U}} \quad \forall u \in \mathbf{U}_{\mathrm{pu}}, v \in \mathbf{V O}_{u}, t \in \mathbf{T}
\end{gathered}
$$

Eq. (1) describes the mass balance at the mixer of unit $u$. Eq. (2) denotes the relation of the product flow rates with the feed flow rate $\left(\mathrm{QF}_{u, t}\right)$, feed properties $\left(f_{u, s}\right.$ is typically a linear function of $\mathrm{PF}_{u, p, t}$ and depends on the unit and outlet stream) and operating variables $\left(V_{u, v, t}\right)$. Eq. (2) is valid for units whose product yields closely depend on petroleum type, such as atmospheric and vacuum distillation columns. The other units operate at constant yields, which means that the function $f_{u, s}\left(\mathrm{PF}_{u, p, t}\right)$ is replaced by a constant parameter. Therefore, Eq. (2) becomes linear for these cases. Eq. (3) describes mass balances at mixers. Eq. (4) represents a weighted average that relates properties of the unit feed stream with properties of the inlet streams. There are cases for which property must be replaced by mixture indices in order to apply Eq. (4) and some properties must be weighted on a mass basis. In the latter cases, the density of the corresponding stream must multiply every term in the numerator and denominator of Eq. (4). Eq. (5) shows the general relationship among outlet properties, feed flowrate, feed properties and operating variables. The functional form of Eq. (5) depends on the unit, stream and property under consideration. Most of the outlet properties are considered to be constant values, and therefore only a few are estimated. Those are usually properties that depend on petroleum types such as sulfur content. Eqs. (6) and (7) denote unit capacity and operating variable domain, respectively.

\subsection{Tank model}

Tank is defined as a piece of equipment where the only two allowed operations are mixture and storage of the different feed streams. Only physical properties can be modified due to mixing. There are two types of tanks in the complex as presented in Section 3: $\mathbf{U}_{f}$ represents the set of tanks dedicated to store crude oil, whereas $\mathbf{U}_{p}$ represents the set 


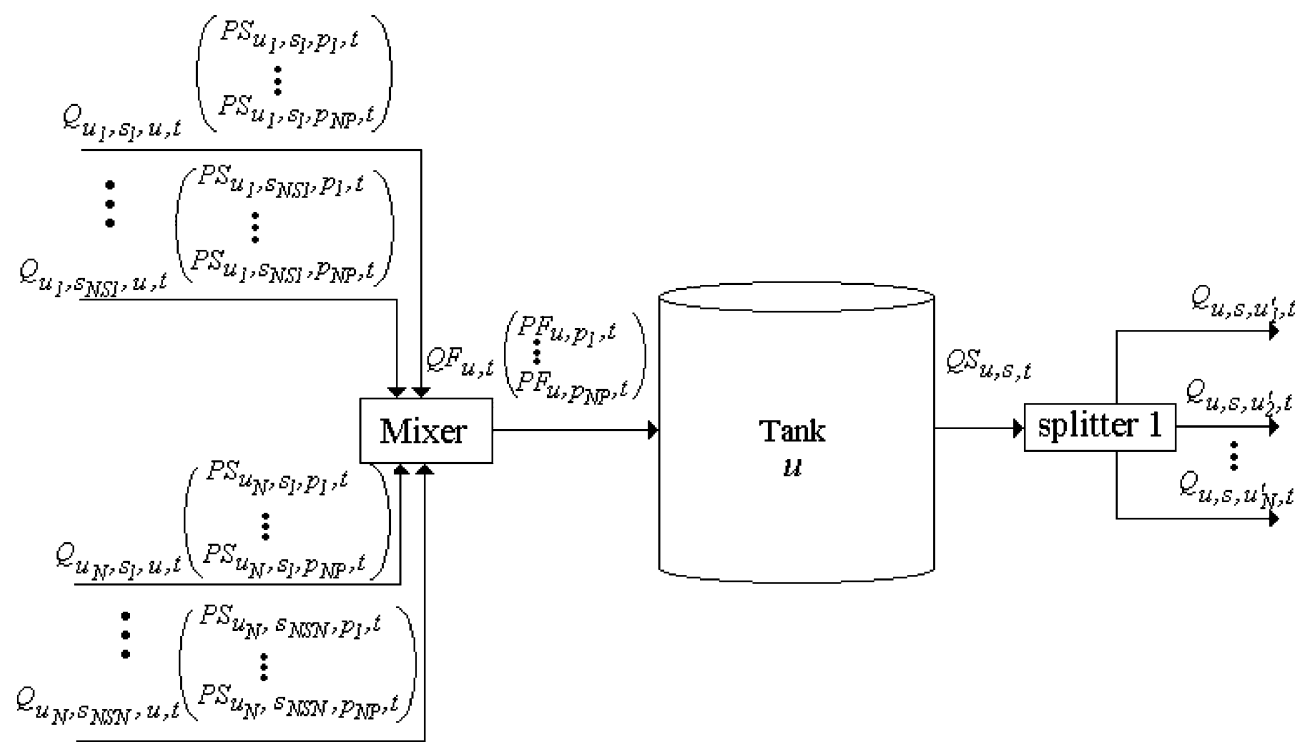

Fig. 6. Model framework for tanks.

of tanks dedicated to store final products. Therefore, the set of tanks in the supply chain is defined as $\mathbf{U}_{\text {tank }}=\left\{\mathbf{U}_{f} \cup \mathbf{U}_{p}\right\}$.

Terminals are composed only of tanks and some of them are facilities used for temporary storing whereas others are used as transshipment points. Tanks at the transshipment terminals and at refineries are demanding points. Therefore, $\mathbf{U}_{\mathrm{dem}}$ is defined as the set tanks that satisfy demand and is contained by the set $\mathbf{U}_{p}$. The following two subsets are contained by the set $\mathbf{U}_{\mathrm{dem}}$ : $\mathbf{U}_{\mathrm{co}}$ that represents product tanks at refinery sites that supply the local market as well as other markets, that is, product tanks at refinery sites connected to the distribution pipeline network and $\mathbf{U}_{\mathrm{nc}}$ that represents the product tanks at refinery sites that supply only local market. Union of these last two sets corresponds to the set of product tanks from refineries, $\mathbf{U}_{r}$.

The general representation of a tank slightly differs from that presented in Fig. 5. The general modeling framework for tanks is depicted in Fig. 6. Tanks may be fed with multiple inlet streams but there is only one outlet stream associated with tanks. According to Fig. 6, the following equations can be written:

$\mathrm{QF}_{u, t}=\sum_{\left(u^{\prime}, s\right) \in \mathbf{U} \mathbf{S}_{u}} Q_{u^{\prime}, s, u, t} \quad \forall u \in \mathbf{U}_{\mathrm{tank}}, t \in \mathbf{T}$

$$
\begin{array}{r}
\mathrm{Vol}_{u, t}=\mathrm{Vol}_{u, t-1}+\mathrm{QF}_{u, t}-\mathrm{Dem}_{u, t}-\mathrm{QS}_{u, s, t} \\
\forall u \in \mathbf{U}_{\text {tank }}, s \in \mathbf{S O}_{u}, t \in \mathbf{T}
\end{array}
$$

$$
\begin{aligned}
\mathrm{QS}_{u, s, t}=\sum_{u^{\prime} \in \mathbf{U} \mathbf{O}_{u, s}} Q_{u, s, u^{\prime}, t} \\
\forall u \in \mathbf{U}_{\mathrm{tank}} \backslash \mathbf{U}_{\mathrm{nc}}, s \in \mathbf{S O}_{u}, t \in \mathbf{T}
\end{aligned}
$$

$$
\begin{aligned}
& y_{u, s, u^{\prime}, t} \cdot Q_{u}^{\mathrm{L}} \leq Q_{u, s, u^{\prime}, t} \leq y_{u, s, u^{\prime}, t} \cdot Q_{u}^{\mathrm{U}} \\
& \quad \forall u \in \mathbf{U}_{\mathrm{tank}} \backslash \mathbf{U}_{\mathrm{nc}}, s \in \mathbf{S O}_{u}, u^{\prime} \in \mathbf{U} \mathbf{O}_{u, s}, t \in \mathbf{T}
\end{aligned}
$$

$$
\begin{gathered}
\operatorname{PF}_{u, p, t}=\frac{\sum_{\left(u^{\prime}, s\right) \in \mathbf{U S}_{u}} Q_{u^{\prime}, s, u, t} \cdot \mathrm{PS}_{u^{\prime}, s, p, t}}{\sum_{\left(u^{\prime}, s\right) \in \mathbf{U S}} Q_{u^{\prime}, s, u, t}} \\
\forall u \in\left\{\mathbf{U}_{\mathrm{co}} \cup \mathbf{U}_{\mathrm{nc}}\right\}, p \in \mathbf{P} \mathbf{I}_{u}, t \in \mathbf{T} \\
\operatorname{Vol}_{u}^{\mathrm{L}} \leq \operatorname{Vol}_{u, t} \leq \operatorname{Vol}_{u}^{\mathrm{U}} \quad \forall u \in \mathbf{U}_{\text {tank }}, t \in \mathbf{T}
\end{gathered}
$$

Eq. (8) describes the mass balance at the mixer of tank $u$ at time period $t$. Eq. (9) denotes inventory variation that depends on the inlet stream and on the two outlet streams, $\mathrm{Dem}_{u, t}$ and $\mathrm{QS}_{u, t}$ that denote demand and outlet flowrate, respectively. Note that Eq. (9) presents the two outlet stream terms for tanks $u \in \mathbf{U}_{\text {tank }} \backslash \mathbf{U}_{\mathrm{nc}}$. Since tanks $u \in \mathbf{U}_{\mathrm{nc}}$ have no connections with other elements of the supply chain, $\mathrm{QS}_{u, s, t}$ in Eq. (9) is dropped in these cases. Moreover, tanks $u \in \mathbf{U}_{f}$ and tanks $u \in \mathbf{U}_{p} \backslash \mathbf{U}_{\mathrm{dem}}$ do not present $\operatorname{Dem}_{u, t}$. Eq. (10) denotes the mass balance at the splitter of tank $u$. Note that the set $\mathbf{S O}_{u}$ contains a single stream which can be further split to be sent to pipelines or processing units (in case $u$ refers to petroleum tanks at refinery sites). Eq. (11) is necessary to avoid transportation of small volumes of petroleum types or products through pipelines, or small charges of petroleum types to distillation columns. Eq. (12) estimates feed properties for every tank $u \in\left\{\mathbf{U}_{\mathrm{co}} \cup \mathbf{U}_{\mathrm{nc}}\right\}$, which represent product tanks at refineries. Properties are not evaluated at terminals. Instead, product quality boundaries are imposed at product tanks at refinery sites. Once property constraints are satisfied at refineries, they are consequently satisfied at terminals. Eq. (13) defines the inventory variable domain.

\subsection{Pipeline model}

Pipeline is defined as a piece of equipment that transports crude oil and products. Neither physical nor chemical properties are modified during transportation. As hypothesis, 


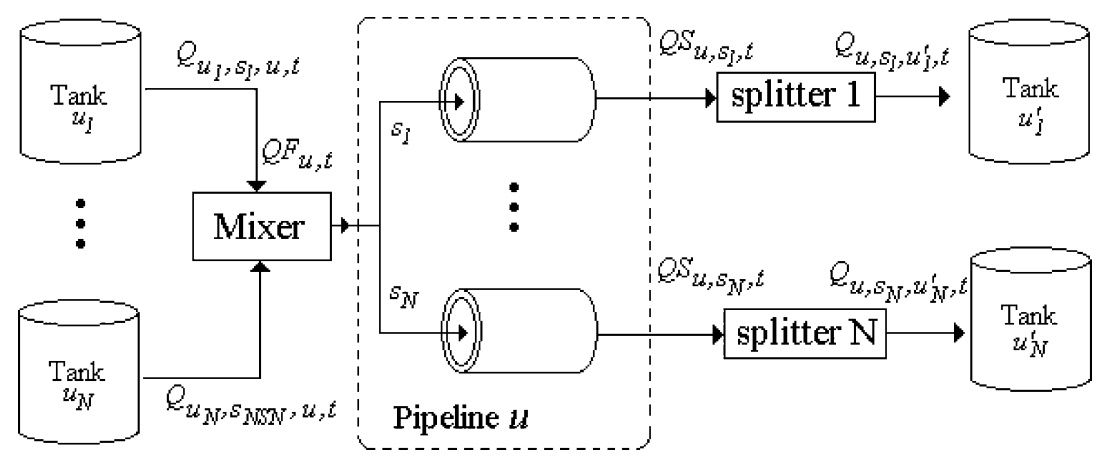

Fig. 7. Model framework for pipelines.

different petroleum types or products are never mixed when transported in pipelines. A well-defined interface is assumed to exist between two different products or petroleum types. Therefore, it is considered that there is no property depletion due to the direct contact between products or petroleum types. Thereby, the general framework for modeling a pipeline is to consider it as a group of units in parallel, as depicted in Fig. 7. Note that every stream fed to the pipeline $u$ passes through it with no contact with other streams. Consequently, the inlet and outlet amounts of every stream are identical. According to Fig. 7 and considering that set $\mathbf{U}_{\text {pipe }}$ represents pipelines that compose pipeline networks in the complex, the following equations can be written:

$\mathrm{QF}_{u, t}=\sum_{\left(u^{\prime}, s\right) \in \mathbf{U S}_{u}} Q_{u^{\prime}, s, u, t} \quad \forall u \in \mathbf{U}_{\text {pipe }}, t \in \mathbf{T}$

$$
\mathrm{QS}_{u, s, t}=Q_{u^{\prime}, s, u, t} \quad \forall\left(u^{\prime}, s\right) \in \mathbf{U S}_{u}, u \in \mathbf{U}_{\text {pipe }}, t \in \mathbf{T}
$$

$$
\begin{aligned}
& \mathrm{QS}_{u, s, t}=Q_{u, s, u^{\prime}, t} \\
& \quad \forall u \in \mathbf{U}_{\text {pipe }}, s \in \mathbf{S O}_{u}, u^{\prime} \in \mathbf{U} \mathbf{O}_{u, s}, t \in \mathbf{T} \\
& \mathrm{QF}_{u, t} \leq \mathrm{QF}_{u}^{\mathrm{U}} \quad \forall u \in \mathbf{U}_{\text {pipe }}, t \in \mathbf{T}
\end{aligned}
$$

Eq. (14) calculates the feed flowrate at the pipeline $u$ at time period $t$. As seen in Fig. 7, pipelines are always supplied by tanks and only tanks are supplied by pipelines. Once a tank is selected to supply pipeline $u$ at time period $t\left(y_{u 1, s 1, u, t}=\right.$ 1, for instance), the lot $Q_{u 1, s 1, u, t}$ is sent to it and the same amount then leaves it as stated in Eq. (15). This equation corresponds to Eq. (2) of processing units. Eq. (16) denotes

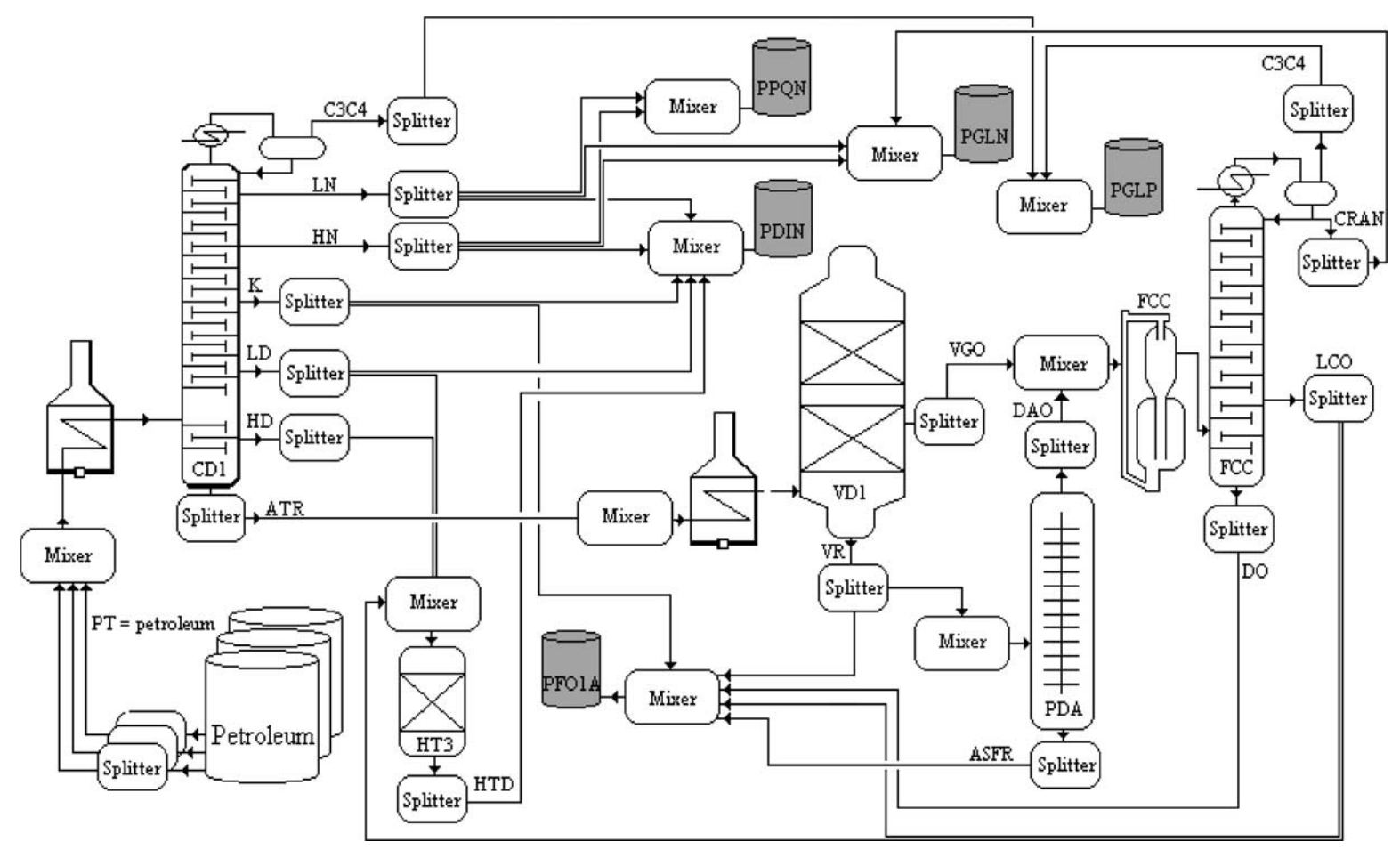

Fig. 8. Simplified REVAP flowsheet-illustrative example. 
the mass balance at mixers of pipeline $u$ for every stream $s$ $\left(s \in \mathbf{S O}_{u}\right)$ transported through it. Note that $\mathbf{U} \mathbf{O}_{u, s}$ denotes a unitary set, since stream $s$ is sent to only one tank. Finally, Eq. (17) defines pipeline capacity.

\subsection{Petroleum supply chain model}

Models of the elements presented in the previous section take part in the set of constraints that compose the optimization problem of the whole complex. The optimization problem is then given as stated in problem PSC. The objective function is defined in Eq. (18) where the maximization of the revenue obtained by the product sales minus costs related to raw material, operation, inventory and transportation is determined. The operating cost is represented by a non-linear term that depends on the unit operating mode. If the unit operates at its design condition, a fixed cost is incurred. Otherwise, a proportional cost is incurred, which depends on the deviation variable $V_{u, v, t}$. Transportation cost depends on the pipeline segment.

Problem PSC:

$$
\begin{aligned}
\operatorname{Max} & Z \\
= & \sum_{u \in \mathbf{U}_{\mathrm{dem}}} \sum_{t \in \mathbf{T}} \mathrm{Cp}_{u, t} \cdot \operatorname{Dem}_{u, t}-\sum_{u \in \mathbf{U}_{\mathrm{port}}} \sum_{t \in \mathbf{T}} \mathrm{Cpet}_{u, t} \cdot \mathrm{QF}_{u, t} \\
& -\sum_{u \in \mathbf{U}_{\mathrm{pu}}} \sum_{t \in \mathbf{T}}\left[\mathrm{Cr}_{u}+\sum_{v \in \mathbf{V O}}\left(\mathrm{Cv}_{u, v} \cdot V_{u, v, t}\right)\right] \cdot \mathrm{QF}_{u, t} \\
& -\sum_{u \in \mathbf{U}_{f}} \sum_{t \in \mathrm{T}} \mathrm{Cinv}_{u} \cdot \mathrm{Vol}_{u, t}-\sum_{u \in \mathbf{U}_{p}} \sum_{t \in \mathbf{T}} \operatorname{Cinv}_{u} \cdot \mathrm{Vol}_{u, t} \\
& -\sum_{u \in \mathbf{U}_{\mathrm{pipe}}} \sum_{t \in \mathbf{T}} \mathrm{Ct}_{u} \cdot \mathrm{QF}_{u, t}
\end{aligned}
$$

subject to:

- Eqs. (1)-(7) to represent processing units at refineries;

- Eqs. (8)-(13) to represent petroleum and product tanks;

- Eqs. (14)-(17) to represent pipelines of crude oil and products.

$$
\begin{aligned}
\mathrm{PF}_{u, p, t}^{\mathrm{L}} \leq \mathrm{PF}_{u, p, t} \leq & \mathrm{PF}_{u, p, t}^{\mathrm{U}} \\
& \forall u \in\left\{\mathbf{U}_{\mathrm{pu}} \cup \mathbf{U}_{\mathrm{co}} \cup \mathbf{U}_{\mathrm{nc}}\right\}, t \in \mathbf{T}
\end{aligned}
$$

$\mathrm{QF}, \mathrm{QS}, Q, \mathrm{Vol} \in \mathfrak{R}^{+} ; \quad \mathrm{PF}, \mathrm{PS}, V \in \mathfrak{R} ; \quad y \in\{0,1\}$

where $\mathbf{U}_{\text {port }}$ is a subset of $\mathbf{U}_{f}$ that represents tanks at the port that store the purchased crude oil from suppliers. Eq. (19) enforces the idea of imposing bounds on feed properties to product tanks at refineries, as well as processing units. The former is usually imposed by environmental regulations and customer specifications, whereas the latter is determined by limitations on processing unit operation. The complete model corresponds to a large-scale mixed-integer nonlinear programming (MINLP) problem, which contains thousands of continuous variables and hundreds of binary variables depending on the planning horizon. It is important to note that the binary variables correspond to the acquisition of crude oil types at every time period as well as the decision of transfer of streams between the several elements of the chain.

Connections among units from the same refinery are accomplished according to the scheme depicted in Fig. 5 and that is illustrated in the next section. Refineries and terminals are connected according to the scheme depicted in Fig. 7. This means that refineries transfer their products to terminals in a tank-pipeline-tank configuration, and vice versa. The same is valid to petroleum transfer. Therefore, there is always a petroleum tank farm and a product tank farm in the refineries (see Figs. 3 and 4). Only few unit-tank or unit-unit connections are allowed, as showed in Figs. 10-13. In this case, the connection framework follows that of Fig. 5. It must be clear that Eq. (3) is responsible for the connection from one unit to another through Eq. (1) or to a tank through Eq. (8). Tanks and pipelines are connected through Eq. (10) that applies to the former and Eq. (14) that holds for the latter. Finally, products leave a pipeline (Eq. (16)) to feed a tank, as enforced in Eq. (8). In summary, the role of variable $Q_{u^{\prime}, s, u, t}$ is to connect variables $\mathrm{QS}_{u^{\prime}, s, t}$ and $\mathrm{QF}_{u, t}$.

\section{Illustrative example}

Application of problem PSC is illustrated by modeling a simplified version of refinery REVAP. The flowsheet based on that of Pinto and Moro (2000) is presented in Fig. 8. The refinery is composed of an atmospheric distillation column (CD1), a vacuum distillation column (VD1), a fluidized catalytic cracking unit (FCC), a propane deasphalting unit (PDA) and a hydrotreating unit (HT3). Atmospheric distillation fractionates crude oil into the following hydrocarbon streams: compounds with 3 and 4 carbon atoms (C3C4), light naphtha (LN), heavy naphtha (HN), kerosene (K), light diesel (LD), heavy diesel (HD) and atmospheric residue (ATR). The vacuum distillation column fractionates the ATR stream from CD1 in two streams: vacuum gas oil (VGO) and vacuum residue (VR). The FCC unit produces light cycle oil (LCO), decanted oil (DO), cracked naphtha (CRAN) and a light hydrocarbon mixture (C3C4). PDA produces deasphalted oil (DAO) and asphaltic residue (ASFR), and HT3 improves product quality by reducing sulfur content (HTD) of its feed stream. Products are identified by their pool names: liquefied petroleum gas (PGLP), interior diesel (PDIN), gasoline (PGLN), petrochemical naphtha (PPQN) and fuel oil (PFO1A). Three crude oil types are available for feeding the refinery: Bonito, Marlin and RGN.

The production planning considering a planning horizon that spans two time periods is given as follows. ${ }^{3}$

\footnotetext{
${ }^{3}$ Mass balances for the outlet streams are not shown for all units. Fig. 8 clearly shows connections among units.
} 


\subsection{Petroleum tank model}

Eqs. (20) and (21) model the outlet streams of petroleum tanks. ${ }^{4}$ Since these are simply mass balances and bound constraints, it is only necessary to define their valid sets that are as follows: $\mathbf{U}_{f}=\{$ Bonito, Marlin, $\mathrm{RGN}\}$ and $\mathbf{T}=$ $\{1,2\}$.

$\mathrm{QS}_{u, \mathrm{PT}, t}=Q_{u, \mathrm{PT}, \mathrm{CD} 1, t} \quad \forall u \in \mathbf{U}_{f}, t \in \mathbf{T}$

$y_{u, t} \cdot 500 \leq \mathrm{QS}_{u, \mathrm{PT}, t} \leq 15000 \cdot y_{u, t} \quad \forall u \in \mathbf{U}_{f}, t \in \mathbf{T}$

\subsection{CD1 model}

The CD1 feed is composed of a petroleum mixture that results from all petroleum types available $\left(\mathbf{U I}_{\mathrm{CD} 1}=\mathbf{U}_{f}\right)$ as stated in Eq. (22):

$\mathrm{QF}_{\mathrm{CD} 1, t}=\sum_{u^{\prime} \in \mathbf{U I}_{\mathrm{CD} 1}} Q_{u^{\prime}, \mathrm{PT}, \mathrm{CD} 1, t} \quad \forall t \in \mathbf{T}$

Moreover, feed flow rate must satisfy CD1 operating capacity:

$14000 \leq \mathrm{QF}_{\mathrm{CD} 1, t} \leq 36000 \quad \forall t \in \mathbf{T}$

Production level depends on the feed flow rate, feed properties and on a single operating variable:

$$
\begin{array}{r}
\mathrm{QS}_{\mathrm{CD} 1, s, t}=\mathrm{QF}_{\mathrm{CD} 1, t} \cdot \mathrm{PF}_{\mathrm{CD} 1, p, t}+\mathrm{QGain}_{\mathrm{CD} 1, s} \cdot V_{\mathrm{CD} 1, V 1, t} \\
\forall s \in \mathbf{S O}_{\mathrm{CD} 1, p} \in \mathbf{P I}_{\mathrm{CD} 1}, t \in \mathbf{T}
\end{array}
$$

where $\mathbf{S O}_{\mathrm{CD} 1}:\{\mathrm{C} 3 \mathrm{C} 4, \mathrm{LN}, \mathrm{HN}, \mathrm{K}, \mathrm{LD}, \mathrm{HD}, \mathrm{ATR}\}$ and $\mathbf{P I}_{\mathrm{CD} 1}$ : $\{\mathrm{YC} 3 \mathrm{C} 4, \mathrm{YLN}, \mathrm{YHN}, \mathrm{YK}, \mathrm{YLD}, \mathrm{YHD}, \mathrm{YATR}\}$. Elements of the set $\mathbf{P I}_{\mathrm{CD} 1}$ denote yields of the outlet streams and depend on the petroleum types fed to the distillation column. The operating variable $V_{\mathrm{CD} 1, V 1, t}$ is the feed temperature deviation (V1). Distillation column is fed at the design temperature value when $V_{\mathrm{CD} 1, V 1, t}=0$ and it yields the distance from the design temperature when $V_{\mathrm{CD} 1, V 1, t} \neq 0$. Temperature deviation of the column feed must also satisfy the following design constraint:

$-10 \leq V_{\mathrm{CD} 1, V 1, t} \leq 10 \quad \forall t \in \mathbf{T}$

Feed properties that appear in Eq. (24) are weighted according to each petroleum type selected to compose the refinery feed:

$$
\begin{array}{r}
\mathrm{PF}_{\mathrm{CD} 1, p, t}=\frac{\sum_{u^{\prime} \in \mathbf{U I}_{\mathrm{CD} 1}} Q_{u^{\prime}, \mathrm{PT}, \mathrm{CD} 1, t} \cdot \operatorname{Prop}_{u^{\prime}, \mathrm{PT}, p}}{\sum_{u^{\prime} \in \mathbf{U I}_{\mathrm{CD} 1}} Q_{u^{\prime}, \mathrm{PT}, \mathrm{CD} 1, t}} \\
\forall p \in \mathbf{P I}_{\mathrm{CD} 1, t \in \mathbf{T}}
\end{array}
$$

\footnotetext{
${ }^{4}$ Outlet streams from petroleum tanks are referred to as PT to denote petroleum.
}

where $\operatorname{Prop}_{u^{\prime}, \mathrm{PT}, p}$ is a parameter that denotes the property $p$ assigned by the petroleum type $u^{\prime}$. Properties of the outlet streams can be modified by the operating variable as in Eq. (26b):

$$
\begin{array}{r}
\mathrm{PS}_{\mathrm{CD} 1, s, p, t}=\operatorname{Prop}_{\mathrm{CD} 1, s, p}+\text { PGain }_{\mathrm{CD} 1, s, p} \cdot V_{\mathrm{CD} 1, V 1, t} \\
\forall s \in \mathbf{S O}_{\mathrm{CD} 1}, p \in \mathbf{P O}_{\mathrm{CD} 1, s}, t \in \mathbf{T}
\end{array}
$$

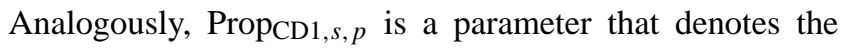
property $p$ of the product stream $s$, and $\mathbf{S O}_{\mathrm{CD} 1}$ and $\mathbf{P O} \mathbf{O}_{\mathrm{CD} 1, s}$ are defined according to the refinery topology and product stream, respectively. The elements of these sets are not shown for the sake of simplicity, since every stream $s \in$ $\mathbf{S O}_{\mathrm{CD} 1}$ defines a set $\mathbf{P O}_{\mathrm{CD} 1, s}$.

Petroleum types characterize both production yields for every product stream of $\mathrm{CD} 1$ and the sulfur content carried by each of these product streams. Consequently, sulfur amount strongly depends on the petroleum types fed into $\mathrm{CD} 1$ and must be estimated through a relation that is similar to Eq. (27a):

$$
\mathrm{PF}_{\mathrm{CD} 1, \mathrm{~S}, t}=\frac{\sum_{u^{\prime} \in \mathbf{U I}_{\mathrm{CD} 1}} Q_{u^{\prime}, \mathrm{PT}, \mathrm{CD} 1, t} \cdot \mathrm{Prop}_{u^{\prime}, \mathrm{PT}, \mathrm{S}}}{\sum_{u^{\prime} \in \mathbf{U I}_{\mathrm{CD} 1}} Q_{u^{\prime}, \mathrm{PT}, \mathrm{CD} 1, t}}
$$

where ' $\mathrm{S}$ ' denotes sulfur and $\operatorname{Prop}_{u^{\prime}, \mathrm{PT}, \mathrm{S}}$ is sulfur content present in the petroleum type $u^{\prime}$.

As seen in Fig. 8 and according to the set $\mathbf{S O}_{\mathrm{CD} 1}$ presented together with Eq. (24), unit CD1 produces seven outlet streams that are sent to other units for further processing or are sent to tanks where they are mixed with other intermediate streams to compose final products. Therefore, seven equations in the form of Eq. (3) are generated. For the sake of illustration, the application of Eq. (3) to the atmospheric residue stream yields:

$$
\mathrm{QS}_{\mathrm{CD} 1, \mathrm{ATR}, t}=\sum_{u^{\prime} \in \mathbf{U} \mathbf{O}_{\mathrm{CD} 1, \mathrm{ATR}}} Q_{\mathrm{CD} 1, \mathrm{ATR}, u^{\prime}, t} \quad \forall t \in \mathbf{T}
$$

where $\mathbf{U} \mathbf{O}_{\mathrm{CD} 1, \mathrm{ATR}}=\{\mathrm{VD} 1\}$. In other words, the ATR stream that leaves CD1 is completely sent to VD1 and therefore the flowrate $Q_{\mathrm{CD} 1, \mathrm{ATR}, \mathrm{VD} 1, t}$ also corresponds to the feed flowrate of unit VD1, as seen in Eq. (28a). Fig. 9 magnifies the connection between these two units and illustrates the flowrate variables involved.

\subsection{VD1 model}

Since VD1 is fed only with atmospheric residue from $\mathrm{CD} 1$, the inlet variables of VD1 are equal to the outlet variables of ATR stream given by the set of Eqs. (28):

$$
\begin{array}{ll}
\mathrm{QF}_{\mathrm{VD} 1, t}=Q_{\mathrm{CD} 1, \mathrm{ATR}, \mathrm{VD} 1, t} & \forall t \in \mathbf{T} \\
\mathrm{PF}_{\mathrm{VD} 1, p, t}=\mathrm{PS}_{\mathrm{CD} 1, \mathrm{ATR}, p, t} & p \in \mathbf{P I}_{\mathrm{VD} 1, t \in \mathbf{T}}
\end{array}
$$

Production yields of the outlet streams, as well as the sulfur content of the inlet stream of the VD1 depend on the 


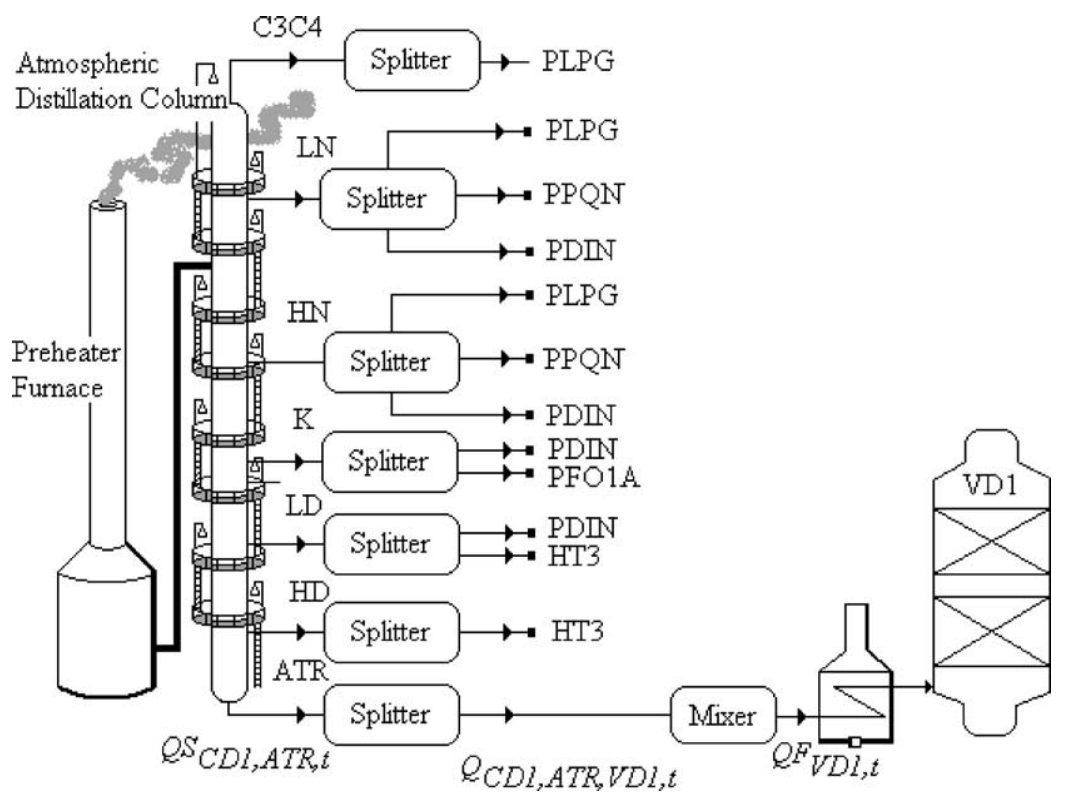

Fig. 9. Connection between CD1 and VD1 for the illustrative example.

petroleum types supplied to the refinery. Therefore, the procedure to determine $\mathbf{P I}_{\mathrm{VD} 1}=\{\mathrm{YVGO}, \mathrm{YVR}, \mathrm{S}\}$ is identical to that of unit CD1. Moreover, since there is no relevant operating variable for VD1, Eqs. (2) and (5) are simplified, respectively, as given in Eqs. (29) and (30).

$$
\begin{array}{ll}
\mathrm{QS}_{\mathrm{VD} 1, \mathrm{VGO}, t}=\mathrm{QF}_{\mathrm{VD} 1, t} \cdot \mathrm{PF}_{\mathrm{VD} 1, \mathrm{YVGO}, t} & \forall t \in \mathbf{T} \\
\mathrm{QS}_{\mathrm{VD} 1, \mathrm{VR}, t}=\mathrm{QF}_{\mathrm{VD} 1, t} \cdot \mathrm{PF}_{\mathrm{VD} 1, \mathrm{YVR}, t} & \forall t \in \mathbf{T}
\end{array}
$$

$\mathrm{PS}_{\mathrm{VD} 1, \mathrm{VGO}, p, t}=$ Prop $_{\mathrm{VD} 1, \mathrm{VGO}, p}$

$$
\forall p \in \mathbf{P O}_{\mathrm{VD} 1, \mathrm{VGO}}, t \in \mathbf{T}
$$

$\mathrm{PS}_{\mathrm{VD} 1, \mathrm{VR}, p, t}=\operatorname{Prop}_{\mathrm{VD} 1, \mathrm{VR}, p} \quad \forall p \in \mathbf{P O}_{\mathrm{VD} 1, \mathrm{VR}}, t \in \mathbf{T}$

where Prop $\mathrm{VD}_{1, \mathrm{VGO}, p}$ and Prop $\mathrm{VD} 1, \mathrm{VR}, p$ are property values of the outlet streams VGO and VR, respectively. Unit VD1 operates within the following range:

$10000 \leq \mathrm{QF}_{\mathrm{VD} 1, t} \leq 24000 \quad \forall t \in \mathbf{T}$

\subsection{PDA model}

Since PDA is exclusively fed by VR from VD1 and no operating variable is considered, the following equations represent inlet and outlet variables:

$$
\begin{aligned}
& \mathrm{QF}_{\mathrm{PDA}, t}=Q_{\mathrm{VD} 1, \mathrm{VR}, \mathrm{PDA}, t} \quad \forall t \in \mathbf{T} \\
& 4000 \leq \mathrm{QF}_{\mathrm{PDA}, t} \leq 7200 \quad \forall t \in \mathbf{T} \\
& \mathrm{PF}_{\mathrm{VD} 1, p, t}=\mathrm{PS}_{\mathrm{VD} 1, \mathrm{VR}, p, t} \quad p \in \mathbf{P I}_{\mathrm{VD} 1}, t \in \mathbf{T}
\end{aligned}
$$

$$
\begin{aligned}
& \mathrm{QS}_{\mathrm{PDA}, \mathrm{DAO}, t}=\text { Yield }_{\mathrm{PDA}, \mathrm{DAO}} \cdot \mathrm{QF}_{\mathrm{PDA}, t} \quad \forall t \in \mathbf{T} \quad \text { (33a) } \\
& \mathrm{QS}_{\mathrm{PDA}, \mathrm{ASFR}, t}=\mathrm{Yield}_{\mathrm{PDA}, \mathrm{ASFR}} \cdot \mathrm{QF}_{\mathrm{PDA}, t} \quad \forall t \in \mathbf{T}
\end{aligned}
$$

$$
\begin{aligned}
& \mathrm{PS}_{\mathrm{PDA}, \mathrm{DAO}, p, t}=\text { Prop }_{\mathrm{PDA}, \mathrm{DAO}, p} \\
& \forall p \in \mathbf{P O}_{\mathrm{PDA}, \mathrm{DAO}}, t \in \mathbf{T}
\end{aligned}
$$

$$
\begin{aligned}
& \mathrm{PS}_{\mathrm{PDA}, \mathrm{ASFR}, p, t}=\text { Prop }_{\mathrm{PDA}, \mathrm{ASFR}, p} \\
& \forall p \in \mathbf{P O}_{\mathrm{PDA}, \mathrm{ASFR}}, t \in \mathbf{T}
\end{aligned}
$$

Product flow rates are calculated from constant yield values as shown in Eq. (33). Note that YieldPDA,DAO and Yield $\mathrm{PDA}, \mathrm{ASFR}$ denote fixed parameters differently from PF used for CD1 and VD1 units. Eq. (34) holds in the case of properties that do not depend on the properties of the inlet stream. Eq. (35) evaluates sulfur content of the product streams of PDA, which depends on the inlet conditions.

$\mathrm{PS}_{\mathrm{PDA}, \mathrm{DAO}, \mathrm{S}, t}=\operatorname{sulfur}_{\mathrm{PDA}, \mathrm{DAO}} \cdot \mathrm{PF}_{\mathrm{PDA}, \mathrm{S}, t} \quad \forall t \in \mathbf{T}$

$\mathrm{PS}_{\mathrm{PDA}, \mathrm{ASFR}, \mathrm{S}, t}=$ sulfurPDA,ASFR $_{\mathrm{P}} \cdot \mathrm{PF}_{\mathrm{PDA}, \mathrm{S}, t} \quad \forall t \in \mathbf{T}$

where sulfurPDA,DAO and sulfurPDA,ASFR are constant parameters.

\subsection{FCC model}

The FCC feed is composed by the combination of DAO from PDA and VGO from VD1 so that feed flow rate is 
determined by Eq. (36) and its operating capacity is expressed by Eq. (37).

$\mathrm{QF}_{\mathrm{VD} 1, t}=Q_{\mathrm{VD} 1, \mathrm{VGO}, \mathrm{FCC}, t}+Q_{\mathrm{PDA}, \mathrm{DAO}, \mathrm{FCC}, t} \quad \forall t \in \mathbf{T}$

$7000 \leq \mathrm{QF}_{\mathrm{FCC}, t} \leq 12500 \quad \forall t \in \mathbf{T}$

Properties of the inlet stream of FCC are calculated through the weighted average of properties of the two streams that compose the FCC feed:

$$
\begin{aligned}
& \mathrm{PF}_{\mathrm{FCC}, p, t}= \\
& \frac{\sum_{\left(u^{\prime}, s\right) \in \mathbf{U I}_{\mathrm{FCC}}} Q_{u^{\prime}, s, \mathrm{FCC}, t} \cdot \mathrm{PS}_{u^{\prime}, s, \mathrm{D} 20, t} \cdot \mathrm{PS}_{u^{\prime}, s, p, t}}{\sum_{\left(u^{\prime}, s\right) \in \mathbf{U I}_{\mathrm{FCC}}} Q_{u^{\prime}, s, \mathrm{FCC}, t} \cdot \mathrm{PS}_{u^{\prime}, s, \mathrm{D} 20, t}} \\
& \forall p \in \mathbf{P I}_{\mathrm{FCC}}, t \in \mathbf{T}
\end{aligned}
$$

where $\mathbf{U I}_{\mathrm{FCC}}=\{(\mathrm{VD} 1, \mathrm{VGO}),(\mathrm{PDA}, \mathrm{DAO})\}$ and density $\mathrm{PS}_{\mathrm{u}^{\prime}, \mathrm{s}, \mathrm{D} 20, \mathrm{t}}$ is used to estimate properties in a mass basis. Product flowrates are not influenced by any operating variable, but depend on carbon residue (RCR) fed to FCC resulting in a special form of Eq. (2):

$$
\begin{aligned}
\mathrm{QS}_{\mathrm{FCC}, s, t}= & \mathrm{QF}_{\mathrm{FCC}, t} \cdot\left[\text { Yield }_{\mathrm{FCC}, s}\right. \\
& \left.+\mathrm{YGain}_{\mathrm{FCC}, s}\left(\mathrm{PF}_{\mathrm{FCC}, \mathrm{RCR}, t}-\mathrm{RC}_{\mathrm{FCC}}\right)\right] \\
& \forall s \in \mathbf{S O}_{\mathrm{FCC}}, t \in \mathbf{T}
\end{aligned}
$$

In Eq. (39), YGain ${ }_{\mathrm{FCC}, s}$ is a flowrate gain parameter related to the carbon residue property $\left(\mathrm{PF}_{\mathrm{FCC}, \mathrm{RCR}, t}\right), \mathrm{RC}_{\mathrm{FCC}}$ is a constant parameter and $\mathbf{S O}_{\mathrm{FCC}}=\{\mathrm{C} 3 \mathrm{C} 4, \mathrm{CRAN}, \mathrm{LCO}$, ATR $\}$. The parameter $\mathrm{YGain}_{\mathrm{FCC}, s}$ may assume either positive or negative values. Properties of the outlet streams are standard values (Eq. (40)), with exception of sulfur content that is defined according to sulfur content at the inlet of FCC (Eq. (41)).

$$
\begin{aligned}
& \mathrm{PS}_{\mathrm{FCC}, s, p, t}=\operatorname{Prop}_{\mathrm{FCC}, s, p} \quad \forall p \in \mathbf{P O}_{\mathrm{FCC}, s}, t \in \mathbf{T} \\
& \mathrm{PS}_{\mathrm{FCC}, s, \mathrm{~S}, t}=\operatorname{sulfur}_{\mathrm{FCC}, s} \cdot \mathrm{PF}_{\mathrm{FCC}, \mathrm{S}, t} \quad \forall t \in \mathbf{T}
\end{aligned}
$$

\subsection{HT3 model}

The unit HT3 is fed by three streams (LD, HD, LCO) that leave two units (CD1, FCC), so that feed flowrate is given by Eq. (42) whereas the operating capacity is bounded by Eq. (43).

$$
\begin{gathered}
\mathrm{QF}_{\mathrm{HT} 3, t}=Q_{\mathrm{CD} 1, \mathrm{LD}, \mathrm{HT} 3, t}+Q_{\mathrm{CD} 1, \mathrm{HD}, \mathrm{HT} 3, t} \\
+Q_{\mathrm{FCC}, \mathrm{LCO}, \mathrm{HT} 3, t} \quad \forall t \in \mathbf{T} \\
3200 \leq \mathrm{QF}_{\mathrm{HT} 3, t} \leq 7500 \quad \forall t \in \mathbf{T}
\end{gathered}
$$

Three properties at the inlet of HT3 must be converted to index form in order to be additive: viscosity (VISCO), flash point (FP) and DASTM 85\% (A85), which limits the content of heavy fractions that are related to large carbon
Table 1

Sets of feed properties for product tanks of the illustrative example

\begin{tabular}{ll}
\hline Product tank & Set of feed properties $\left(\mathbf{P I}_{u}\right)$ \\
\hline PGLP & $\{$ PVR, MON $\}$ \\
PGLN & $\{$ PVR, MON $\}$ \\
PDIN & $\{$ FP, A50, A85, S, NC, D20 \\
PFO1A & $\{$ S, VISCO $\}$ \\
PPQN & $\varnothing$ \\
\hline
\end{tabular}

Table 2

Volume of petroleum purchased of the illustrative example $\left(\mathrm{m}^{3}\right)$

\begin{tabular}{lcc}
\hline Tank & Time period 1 & Time period 2 \\
\hline Bonito & 0 & 1341 \\
Marlin & 9649 & 9420 \\
RGN & 15000 & 15000 \\
\hline
\end{tabular}

residue and poor color. Their mixture indices are calculated by Eqs. (44)-(46).

$$
\begin{aligned}
I_{u^{\prime}, s, \mathrm{VISCO}, t}=\frac{\log _{10} P_{u^{\prime}, s, \mathrm{VISCO}, t}}{\log _{10} 1000 P_{u^{\prime}, s, \mathrm{VISCO}, t}} & \quad \forall\left(u^{\prime}, s\right) \in \mathbf{U S}_{\mathrm{HT} 3}, t \in \mathbf{T}
\end{aligned}
$$

Table 3

Production and inventory levels of the illustrative example

\begin{tabular}{lccccc}
\hline Tanks & \multicolumn{2}{l}{$\begin{array}{l}\text { Production level } \\
\left(\mathrm{QF}_{u, t}\right)\left(\mathrm{m}^{3}\right)\end{array}$} & & \multicolumn{2}{l}{$\begin{array}{l}\text { Inventory level } \\
\left(\mathrm{Vol}_{u, t}\right)\left(\mathrm{m}^{3}\right)\end{array}$} \\
\cline { 2 - 3 } \cline { 6 - 6 } & $\begin{array}{l}\text { Time } \\
\text { period } 1\end{array}$ & $\begin{array}{l}\text { Time } \\
\text { period 2 }\end{array}$ & & $\begin{array}{l}\text { Time } \\
\text { period 1 }\end{array}$ & $\begin{array}{l}\text { Time } \\
\text { period 2 }\end{array}$ \\
\hline PGLP & 689 & 487 & & 2689 & 2798 \\
PPQN & 0 & 0 & 200 & 250 \\
PGLN & 1152 & 2716 & & 6152 & 6364 \\
PDIN & 615 & 0 & & 11115 & 11385 \\
PFO1A & 1632 & 3061 & & 5232 & 5730 \\
\hline
\end{tabular}

Table 4

Product properties and bounds of the illustrative example

\begin{tabular}{llcccc}
\hline $\begin{array}{l}\text { Product } \\
\text { tank }\end{array}$ & Property & $\begin{array}{l}\text { Lower } \\
\text { bound }\end{array}$ & \multicolumn{2}{l}{ Time period } & \multirow{2}{*}{$\begin{array}{l}\text { Upper } \\
\text { bound }\end{array}$} \\
\cline { 4 - 5 } & & & 1 & 2 & \\
\hline PGLP & MON & & 83 & 83 & \\
& PVR & & 5.00 & 4.96 & 15 \\
PGLN & MON & 81 & 82 & 82 & \\
& PVR & 0.3 & 1.00 & 0.55 & 0.7 \\
PDIN & FP & & 0 & 0 & \\
& A50 & 245 & 279.83 & 279.78 & 313 \\
& A85 & 300 & 357.94 & 358.64 & 370 \\
& S & & 0.14 & 0.13 & 0.5 \\
& NC & 40 & 43.18 & 43.27 & \\
& D20 & 0.82 & 0.82 & 0.82 & 0.88 \\
PFO1A & S & & 0.8 & 0.81 & 2.5 \\
& VISCO & & 0.48 & 0.45 & 0.48 \\
\hline
\end{tabular}




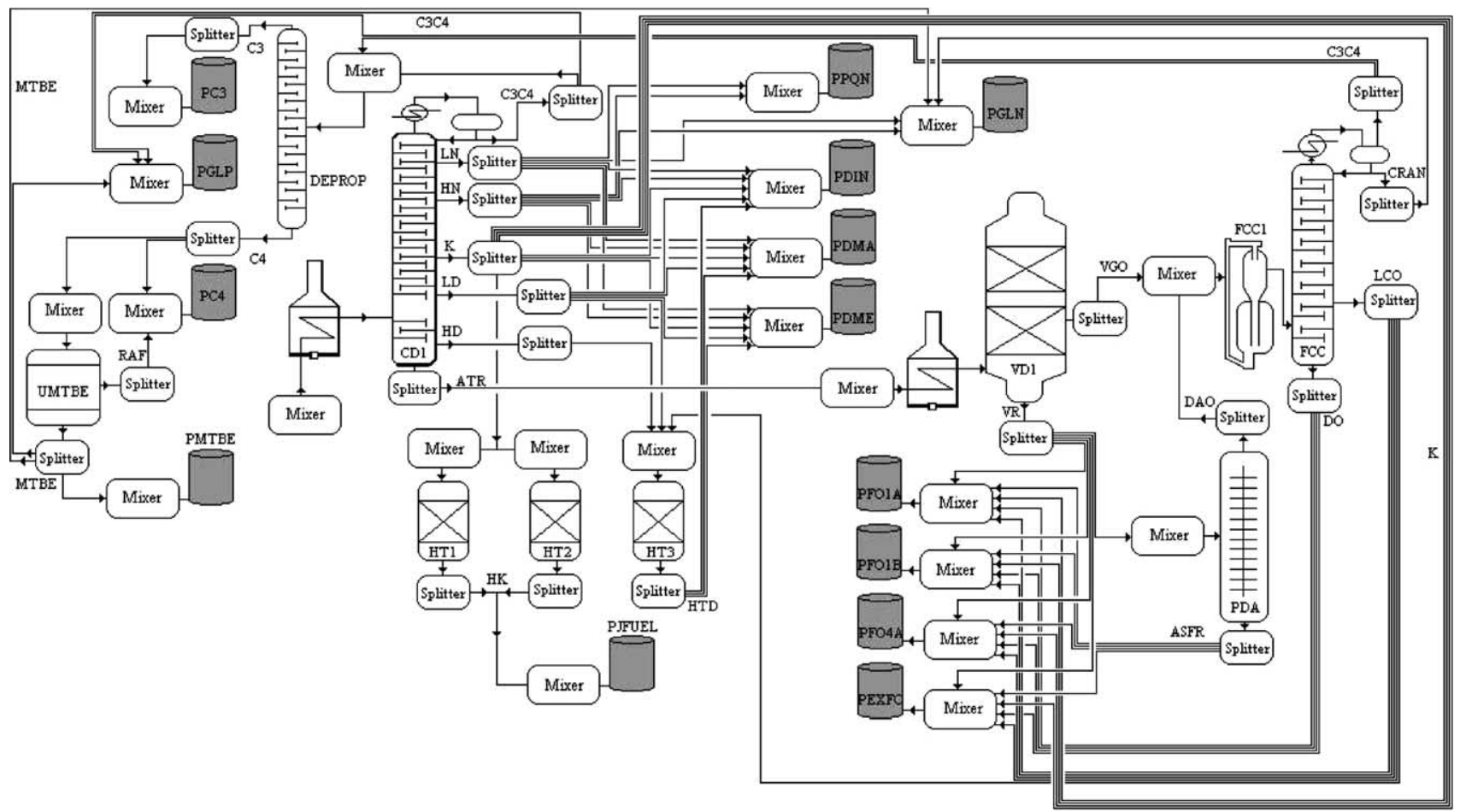

Fig. 10. REVAP flowsheet.

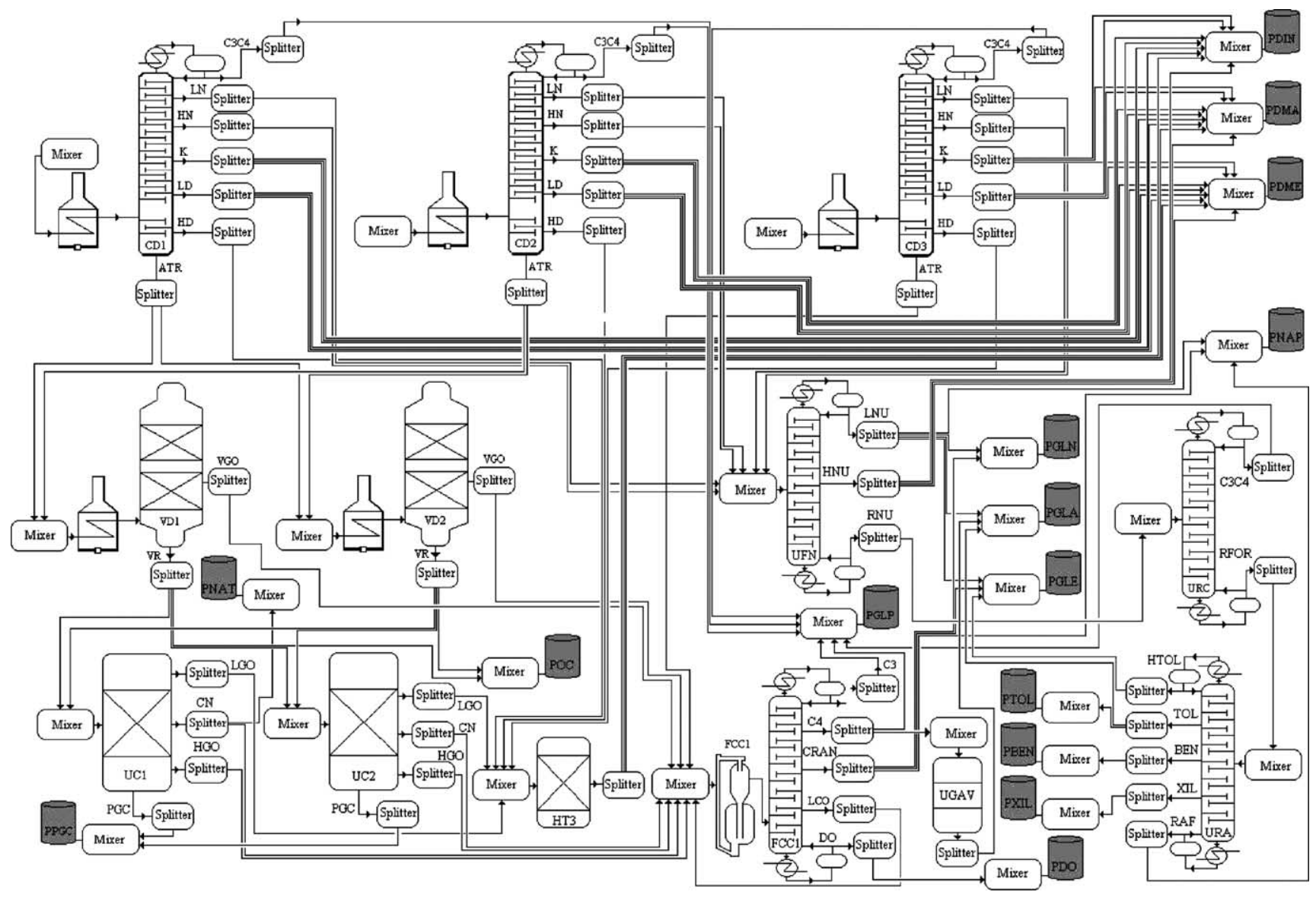

Fig. 11. RPBC flowsheet. 


$$
\begin{array}{r}
I_{u^{\prime}, s, \mathrm{FP}, t}=\exp \left[\frac{10006.1}{1.8 P_{u^{\prime}, s, \mathrm{FP}, t}+415}-14.0922\right] \\
\forall\left(u^{\prime}, s\right) \in \mathbf{U S}_{\mathrm{HT} 3}, t \in \mathbf{T} \\
I_{u^{\prime}, s, \mathrm{~A} 85, t}=\left(\frac{1.8 P_{u^{\prime}, s, \mathrm{~A} 85, t}+32}{549}\right)^{7.8} \\
\forall\left(u^{\prime}, s\right) \in \mathbf{U S}_{\mathrm{HT} 3}, t \in \mathbf{T}
\end{array}
$$

Once these mixture indices have been determined, properties of the inlet stream of HT3 can be evaluated through Eq. (4). The exception is property A85 that must be calculated by Eq. (47).

$$
\begin{aligned}
& \mathrm{PF}_{\mathrm{FCC}, \mathrm{A} 85, t} \\
& =305\left(\frac{\sum_{\left(u^{\prime}, s\right) \in \mathbf{U I}_{\mathrm{FCC}}} Q_{u^{\prime}, s, \mathrm{FCC}, t} \cdot I_{u^{\prime}, s, \mathrm{~A} 85, t}}{\sum_{\left(u^{\prime}, s\right) \in \mathbf{U I}_{\mathrm{FCC}}} Q_{u^{\prime}, s, \mathrm{FCC}, t}}\right)^{0.128} \\
& \quad-17.78 \quad \forall p \in \mathbf{P I}_{\mathrm{FCC}, t \in \mathbf{T}}
\end{aligned}
$$

Outlet flow rate equals inlet flow rate as well as most of the properties at the outlet stream. Exception is made to sulfur content $(S)$ and cetane number $(N C)$ that depend on an operating variable and are calculated through Eqs. (48) and (49), where $\mathrm{VR}_{\mathrm{HT} 3, \mathrm{~S}}$ and $\mathrm{VR}_{\mathrm{HT}, \mathrm{CN}}$ are constant parameters. Operating variable range must assume values within the interval defined through Eq. (50).

$$
\begin{array}{r}
\mathrm{PS}_{\mathrm{HT} 3, \mathrm{HTD}, \mathrm{S}, t}=\mathrm{PF}_{\mathrm{HT} 3, \mathrm{~S}, t} \cdot\left(\mathrm{VR}_{\mathrm{HT} 3, \mathrm{~S}}-V_{\mathrm{HT} 3, \mathrm{~V} 1, t}\right) \\
\forall t \in \mathbf{T}
\end{array}
$$

$$
\begin{array}{r}
\mathrm{PS}_{\mathrm{HT} 3, \mathrm{HTD}, \mathrm{CN}, t}=\mathrm{PF}_{\mathrm{HT} 3, \mathrm{CN}, t}-\mathrm{VR}_{\mathrm{HT} 3, \mathrm{CN}} \cdot V_{\mathrm{HT} 3, \mathrm{~V} 1, t} \\
\forall t \in \mathbf{T}
\end{array}
$$

$50 \leq V_{\mathrm{HT} 3, \mathrm{~V} 1, t} \leq 90 \quad \forall t \in \mathbf{T}$

\subsection{Product tank model}

Product tanks for the illustrative example serve local markets and therefore are modeled as such. In this case, Eqs. (8), (9), (12) and (13) are applied. Eqs. (8), (9) and (13) are straightforward and will not be shown. The complicating constraints are those related to feed properties assessment. Table 1 presents the set of feed properties $\left(\mathbf{P I}_{u}\right)$ of each product tank $\left(u \in \mathbf{U}_{p}\right)$. From the properties listed in Table 1, PVR, MON, A50, and D20 are calculated according to Eq. (12). Properties $S$ and NC are calculated on a mass basis. Therefore Eq. (12) must include the density in the same way as done in Eq. (38). Properties A85, FP and VISCO follow the same procedure described for the FCC unit.

The refinery model corresponds to a mixed-integer nonlinear programming (MINLP) problem, which contains 383 variables and 349 equations. Six binary variables are necessary for the decision of purchasing crude oil (three for each

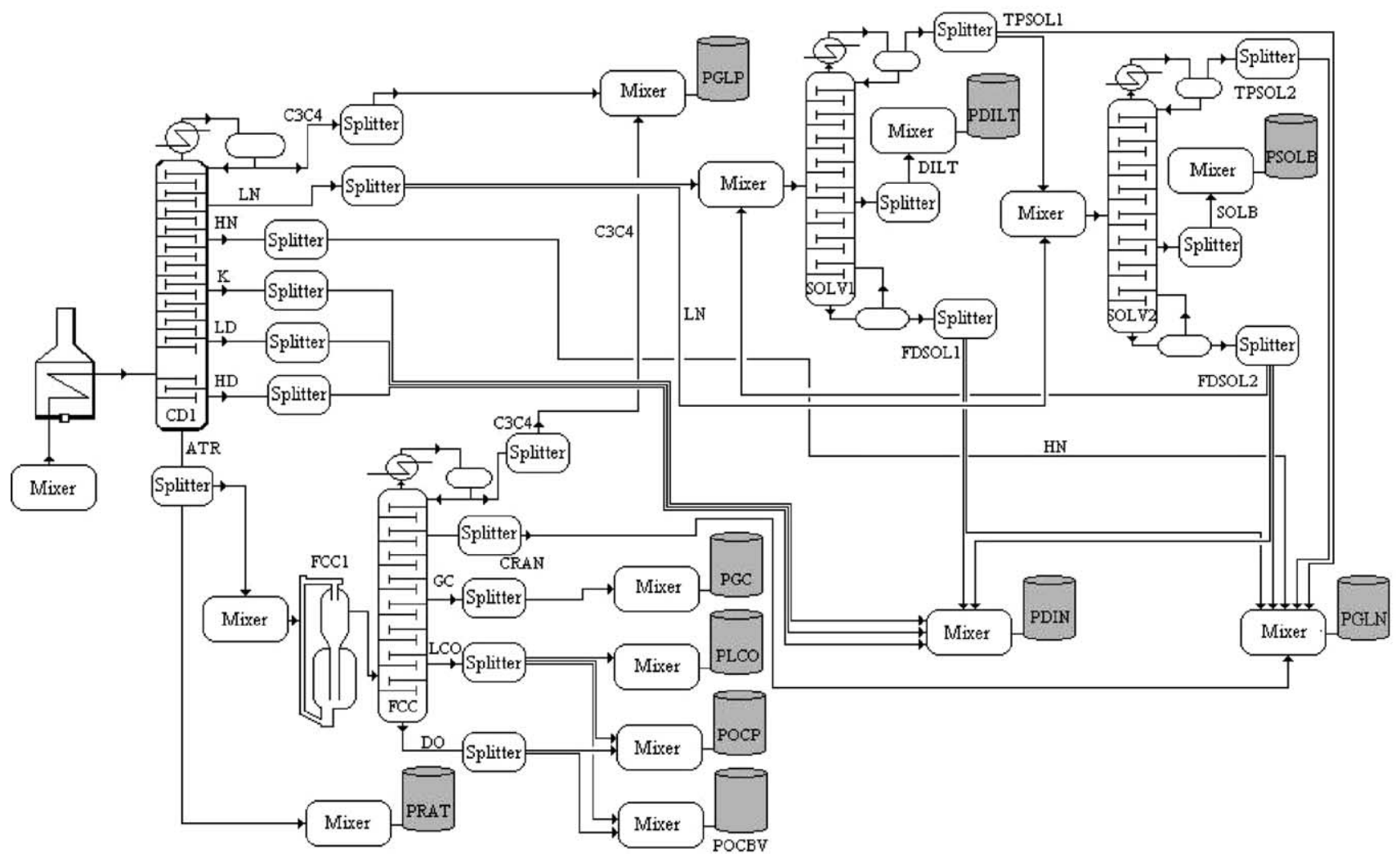

Fig. 12. RECAP flowsheet. 
time period). The model was implemented in the modeling system GAMS (Brooke, Kendrick, \& Meeraus, 1998) and solved with DICOPT (Viswanathan \& Grossmann, 1990). The NLP subproblems were solved with CONOPT2 (Drud, 1994), whereas the MILP master problems were solved with OSL (IBM, 1991). Overall, 1.98 CPU seconds were necessary to solve the problem. NLP sub-problems represent nearly $75 \%$ of total solution time. Table 2 presents results of the amount required of each petroleum type. Table 3 shows production and inventory levels for each period and Table 4 presents the optimal product properties calculated and their specifications.

Eqs. (29), (38) and (44)-(47) are critical constraints because of their high non-linearity and the wide domain of variables. This fact requires the problem to be carefully scaled and bounded. Another important aspect is that concerning starting point. Since the formulation results a non-convex NLP problem, different starting points may lead to different local optima. However, computational tests with different starting points led to the same solution.

\section{Petroleum supply chain-case study}

This section is divided in two parts. The first part presents further details in the description of the targeted petroleum supply chain whereas the second part presents results and discussion obtained through the implementation of problem PSC for the case study.

\subsection{Case study revisited}

The previous section illustrated how complex problem PSC can be even for a relatively small example. Actually, even the small example can be further complicated if the time horizon is extended. For the petroleum supply chain described in Section 3.2, refinery models follow the same idea presented in the previous section, except that each refinery presents a particular configuration as well as sets of processing units and petroleum and product tanks. Therefore, the approach is to formulate model for refineries according to the processing unit and tank models presented in Section 4.

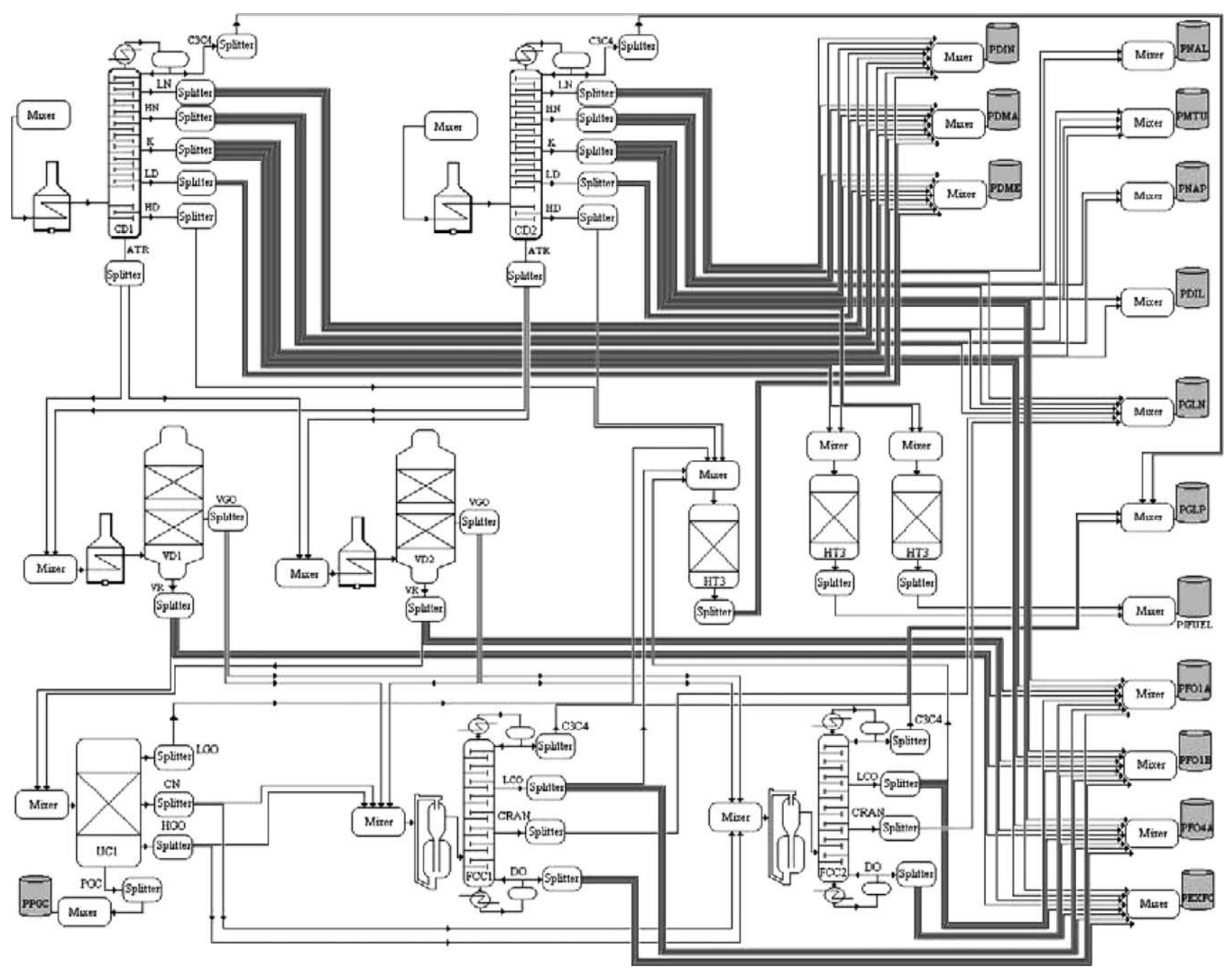

Fig. 13. REPLAN flowsheet. 


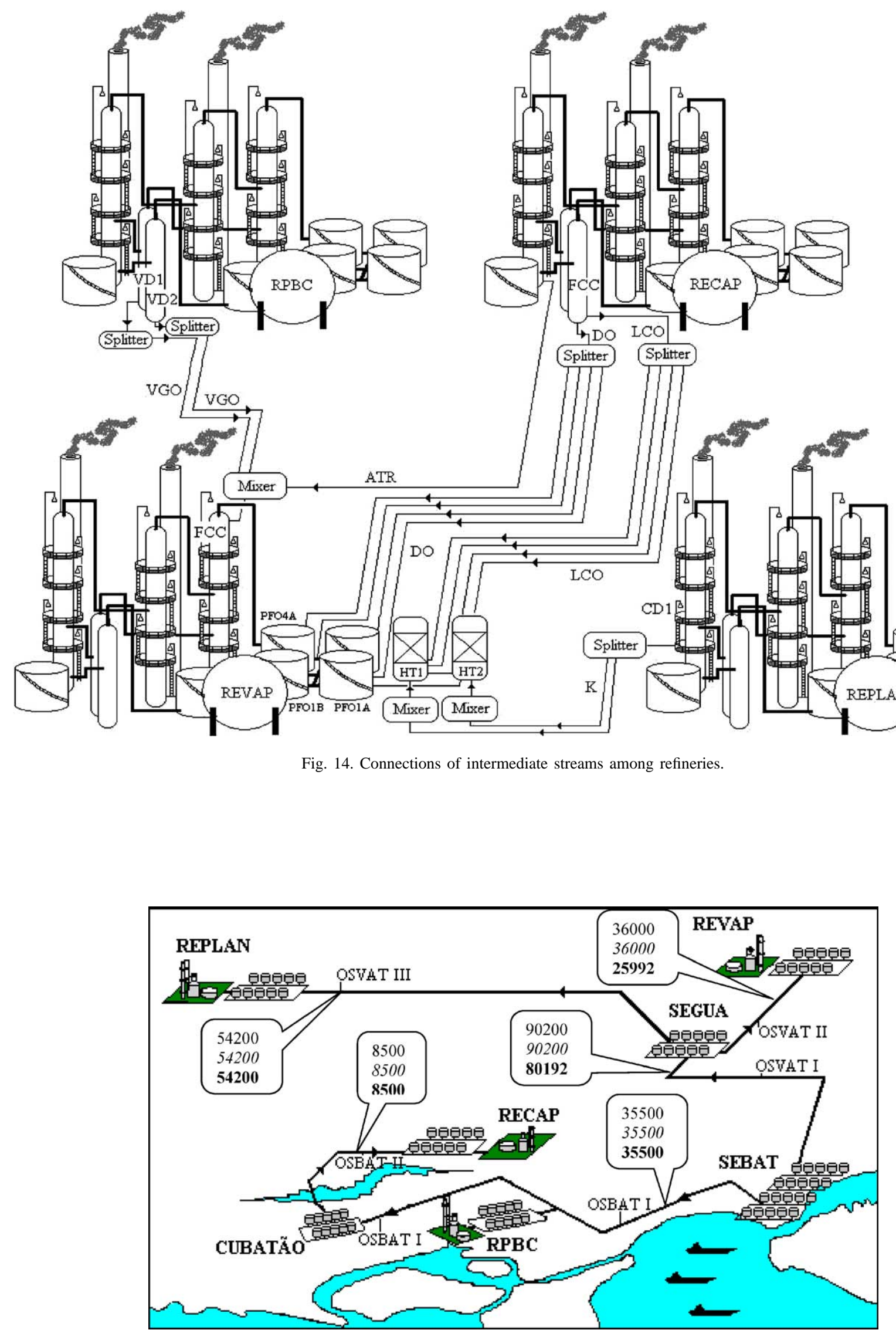

Fig. 15. Comparison of the petroleum distribution for the three cases. 
Terminal models are formulated based on the tank model and connections among facilities are modeled according to the pipeline model. Figs. 10-13 present topologies of the REVAP, RPBC, RECAP and REPLAN refineries, respectively. Symbols used to describe processing units, product tanks and intermediary streams are described in the notation section. The REVAP refinery is composed of 8 units and has a processing capacity of $36000 \mathrm{~m}^{3}$ per day of crude oil that is converted in 14 products. The RPBC refinery is composed of 13 units and has a processing capacity of $27000 \mathrm{~m}^{3}$
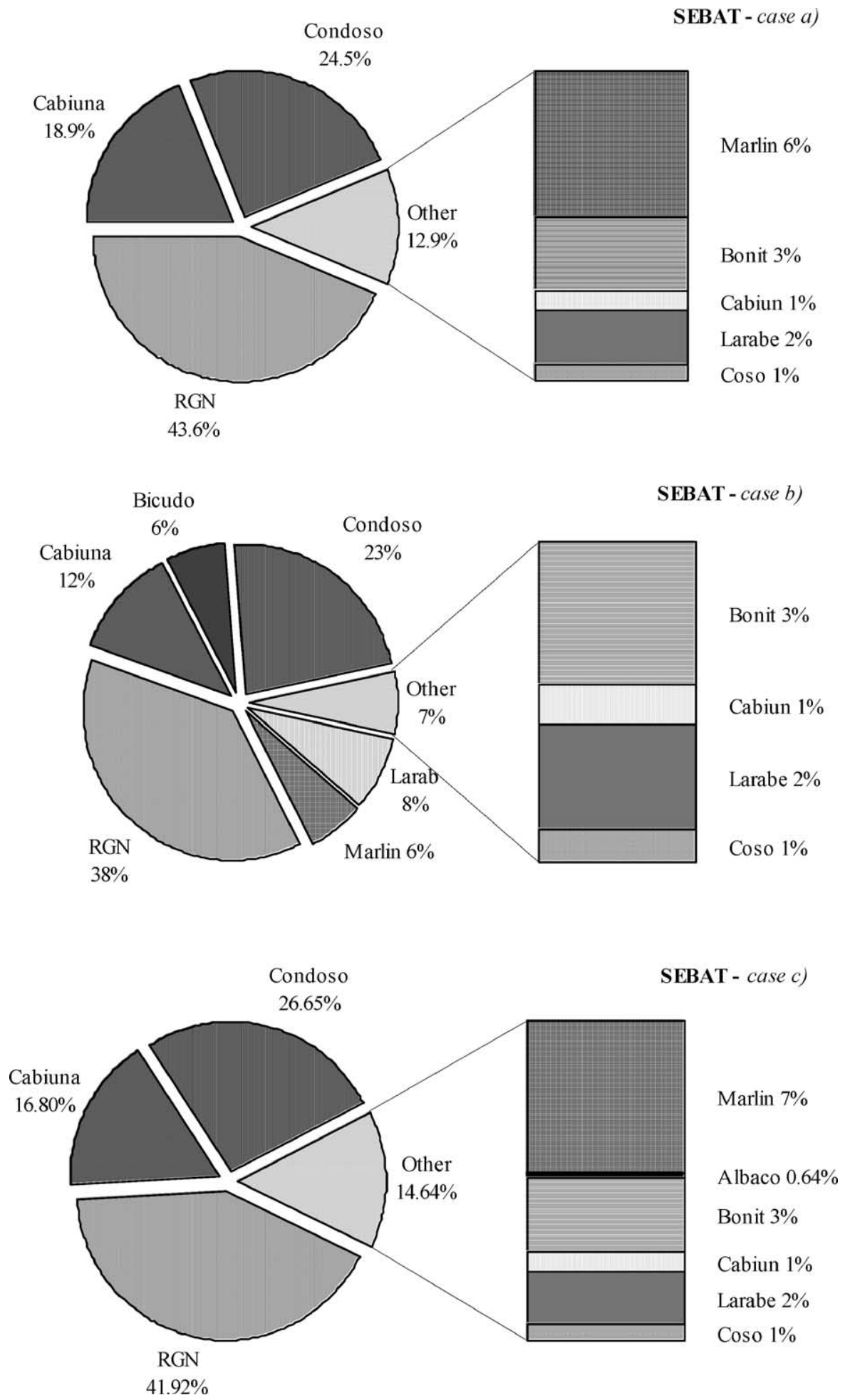

Fig. 16. Interference on the petroleum type selection. 
per day of crude oil that is converted in 15 products. The topology of the refinery RECAP is as follows: there are 4 units with a processing capacity of $8500 \mathrm{~m}^{3}$ per day of crude oil that is converted in 10 products. The REPLAN refinery is composed of 10 units and has a processing capacity of $54200 \mathrm{~m}^{3}$ per day of crude oil that is converted in 15 products.

Besides connections of final products among refineries and terminals described in Section 3.2, connections of intermediate streams among refineries are also allowed. Such possible connections are illustrated in Fig. 14. Units VD1 and VD2 from RPBC can either send VGO to be processed at its own FCC unit or send it to the FCC unit from REVAP. Moreover, CD1 from RECAP can either send ATR to be processed at FCC from its site or send it to FCC from REVAP. Another possibility is to use DO and LCO produced at RECAP to compose products at its site or send those streams to compose fuel oil products at REVAP. Finally, K produced at CD1 at REPLAN may be sent to be processed at HT1 or HT2 at REVAP.

\subsection{Results and discussion}

In this section, results of the problem PSC are compared to two other cases in which additional constraints are included. The model was implemented in the modeling system GAMS (Brooke et al., 1998) and solved with DICOPT (Visvanathan \& Grossmann, 1990). The NLP subproblems were solved with CONOPT2 (Drud, 1994), whereas the MILP master problems were solved with CPLEX (ILOG, 1999).

The original problem is compared to a first scenario in which refinery REVAP is assigned lots of certain petroleum types and to a second scenario in which the pipeline segment SG-RV of the product distribution network is temporarily interrupted for maintenance. The three cases are summarized as follows:

\begin{tabular}{ll}
\hline Case (a) & Original problem PSC \\
Case (b) & $\begin{array}{l}\text { A minimum amount of } 10000 \mathrm{~m}^{3} \text { for } \\
\text { petroleum type Larab and } 8000 \mathrm{~m}^{3} \text { for } \\
\text { petroleum type Bicudo must be ordered due } \\
\text { to a contract agreement with their suppliers }\end{array}$ \\
Case (c) & $\begin{array}{l}\text { Operation of pipeline segment SG-RV is } \\
\text { interrupted for maintenance }\end{array}$ \\
\hline
\end{tabular}

The input data is presented in Appendix A. Table A.1 presents prices of petroleum types from all possible suppliers. Table A. 2 presents inventory costs for petroleum and product tanks, Table A.3 presents transportation costs for petroleum and product pipeline networks and Table A.4 presents product sale prices and demands for refineries and terminals.

Fig. 15 shows a comparison of the petroleum amounts sent to refineries of the complex for the three cases. The nor- mal font values in the callouts represent results for case (a) the italic values represent results for case (b) and the bold face values represent results for the case (c). It can be seen that the overall petroleum load for refineries RPBC, RECAP and REPLAN are unaffected by the perturbations imposed on the refinery REVAP. Interruption of the pipeline segment SG-RV causes a significant $10000 \mathrm{~m}^{3}$ drop of the overall petroleum load to refinery REVAP, since product distribution is hindered by the pipeline stoppage. This perturbation causes also a small impact on the petroleum selection as seen in Fig. 16. For case (b), on the other hand, the impact
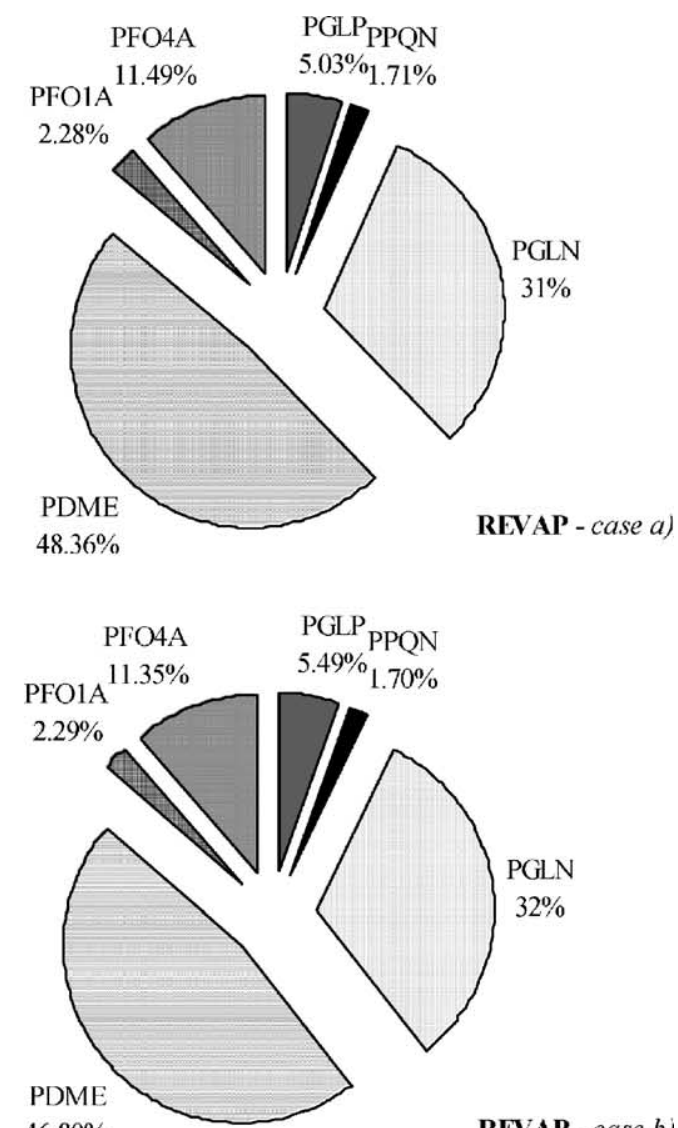

$46.80 \%$

REVAP - case b)

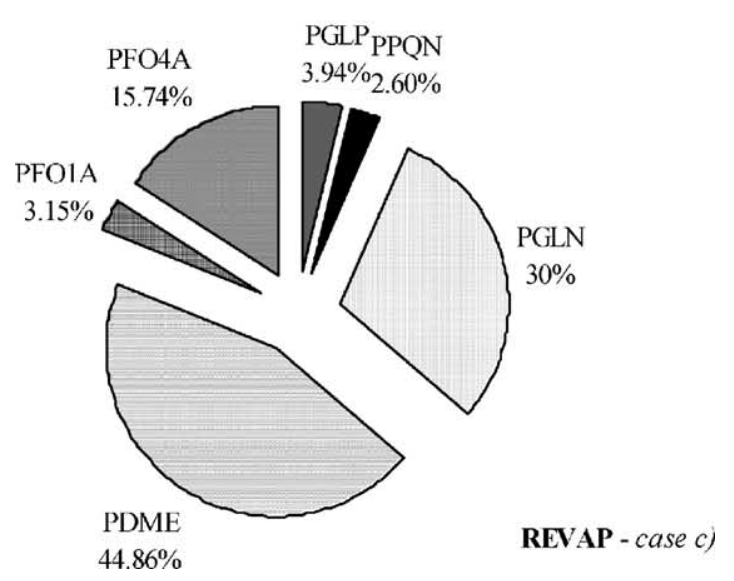

Fig. 17. Interference on the production level of refinery REVAP. 

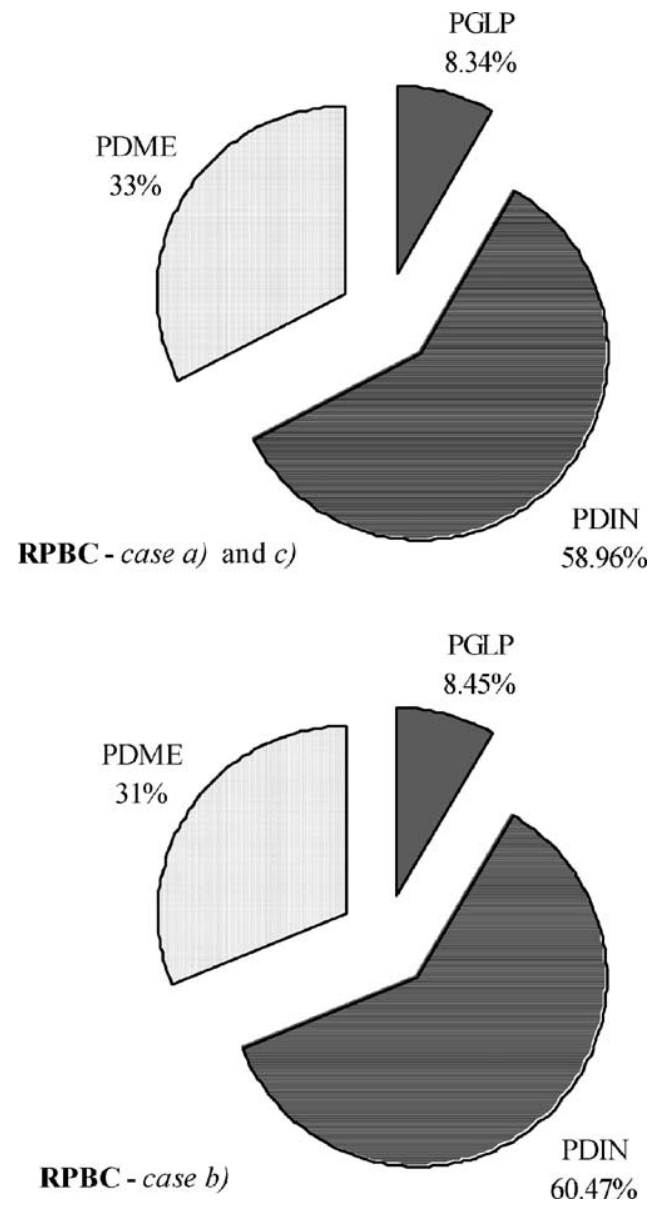

Fig. 18. Interference on the production level of refinery RPBC.

is doubtless more significant. Fig. 16 shows the reduction of the load of petroleum types RGN and Cabiun in favor of petroleum types Larab and Bicudo acquirement imposition.

Analyzing the refineries production planning, it can be realized that the additional constraints given in case (b) enforce re-planning of the entire complex, as verified in Figs. 17-20. Comparison between case (a) and case (b) reveals that the change in petroleum types selection tries to compensate the disadvantage that case (b) presents with the partial pre-selection of petroleum types. Actually, for most of the products planning of the supply chain is not changed at all. The more relevant impacts on production planning are observed to PDME from REVAP, PDME and PDIN from

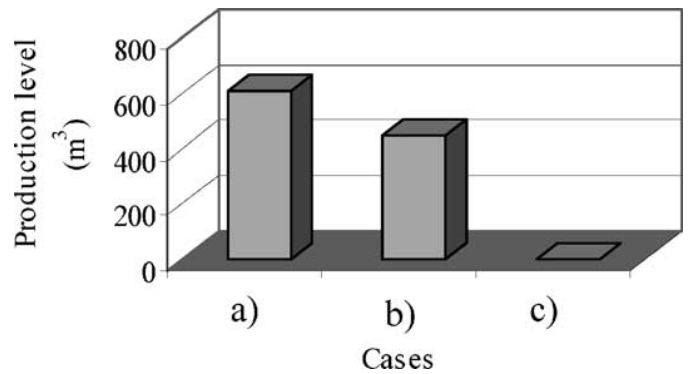

Fig. 19. Interference on the production level of refinery RECAP.
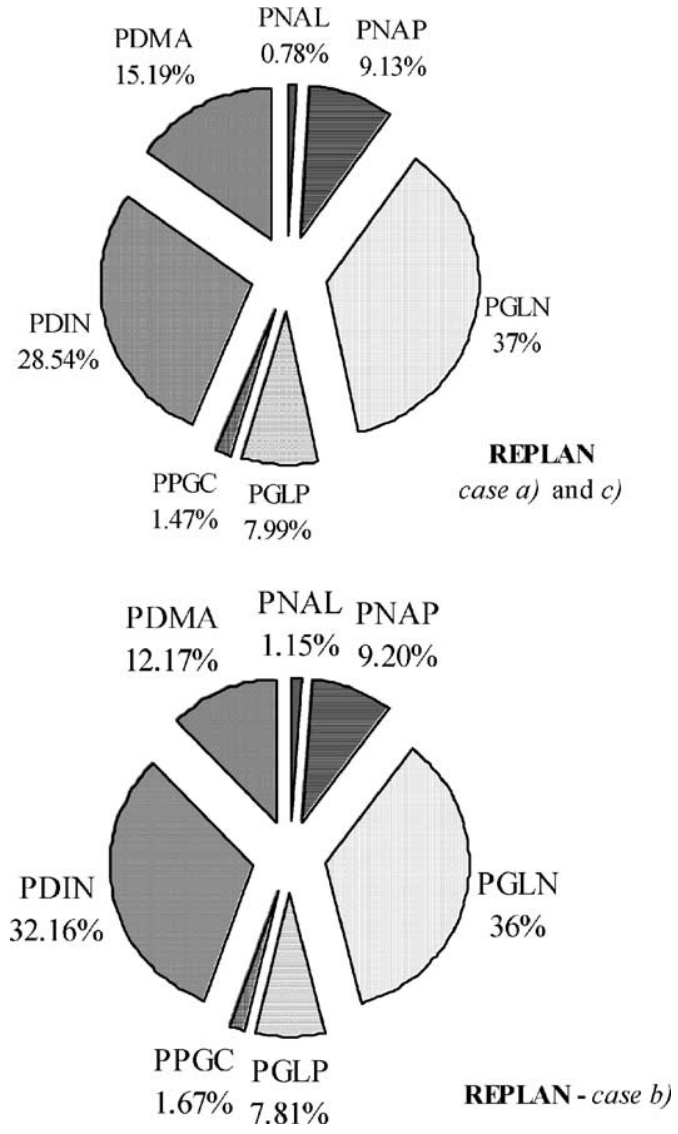

Fig. 20. Interference on the production level of refinery REPLAN.

RPBC, POCBV from RECAP and PDMA and PDIN from REPLAN. These tanks, with exception of POCBV, are directly connected to the pipeline distribution network. This means that the distribution planning is also altered to adjust the additional constraints of case (b). The variation for the POCBV tank can be explained by the connection of the intermediate streams DO and LCO from refinery RECAP to refinery REVAP (see Figs. 12 and 14). The perturbation caused by case (c) has smaller effect on refineries production. Actually, only refinery REVAP is directly impacted by the interruption of pipeline segment SG-RV that causes increase of the inventory level for some products due to the deficient distribution (Fig. 21).

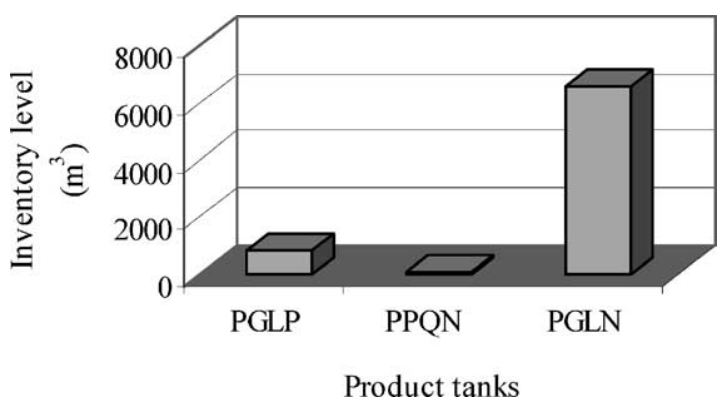

Fig. 21. Inventory level for product tanks from refinery REVAP under constraints of case c). 

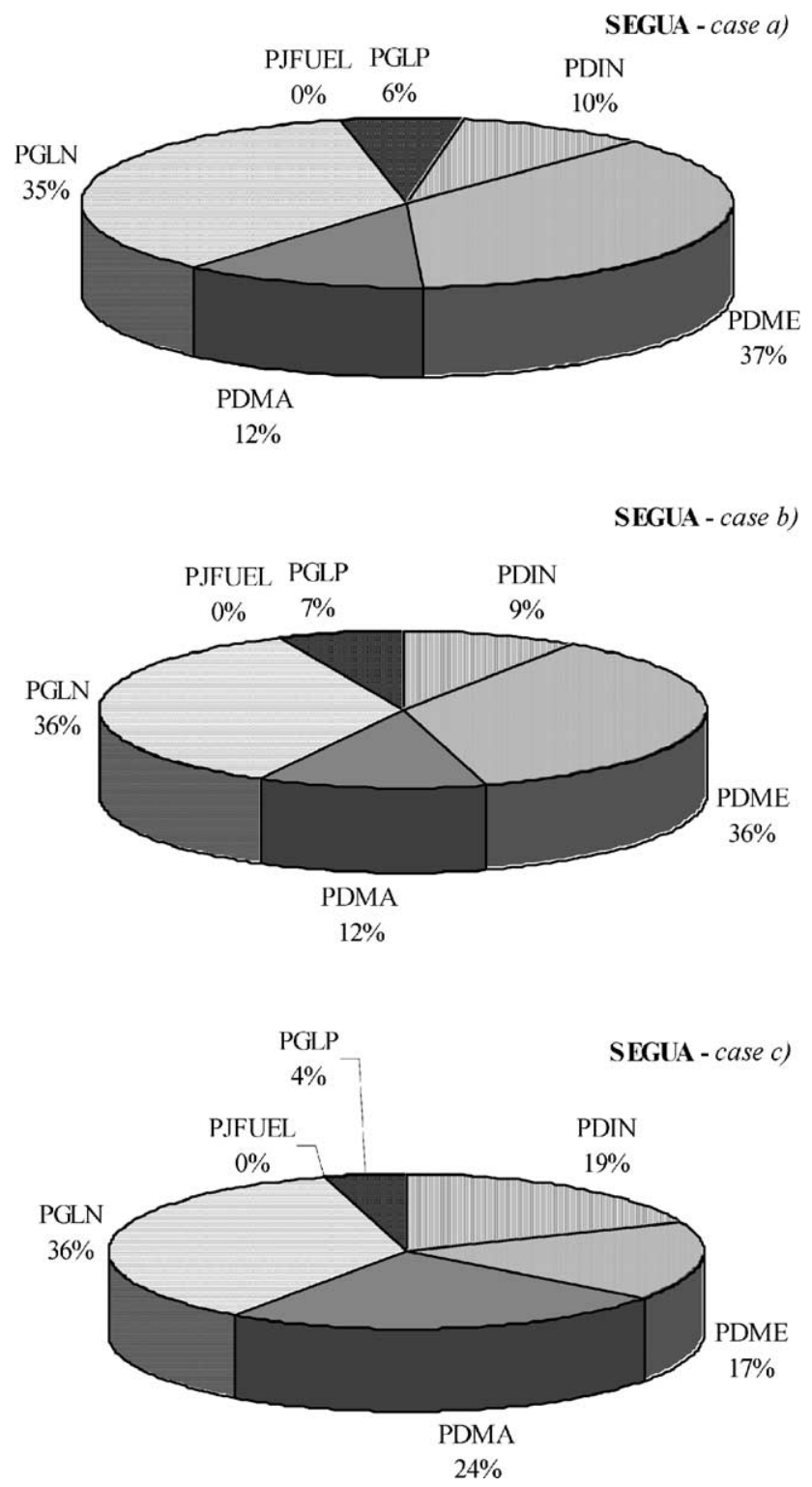

Fig. 22. Products feed flowrate percentage at terminal SEGUA.

Indeed, distribution planning plays an important role by attempting to balance interferences suffered in the supply chain as observed how refineries react to the constraints imposed on the system. Likewise, there is an impact on the distribution facilities. Figs. 22-25 show the percentage of each product transferred to terminals, whereas Fig. 26 shows the total amount to be transported by each product pipeline according to the production planning. Again, the values in normal font in the callouts represent results for case (a) the values in italics represent results for case (b) and the values in bold face represent results for the case (c). For case (b), it is observed that only little variations are established. For case (c), on the other hand, larger variations can be observed. Since all refineries are needed to satisfy the demand requirements of the whole chain, products from refinery RE-

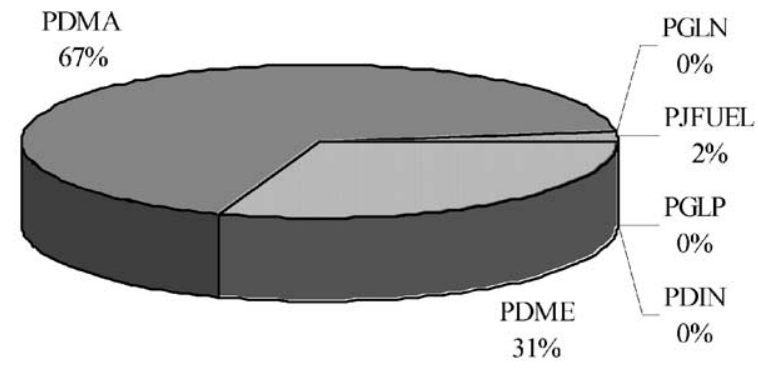

SCS - case a)

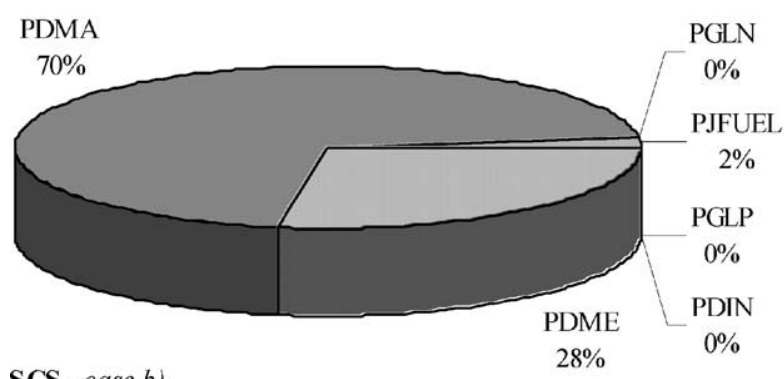

SCS - case b)

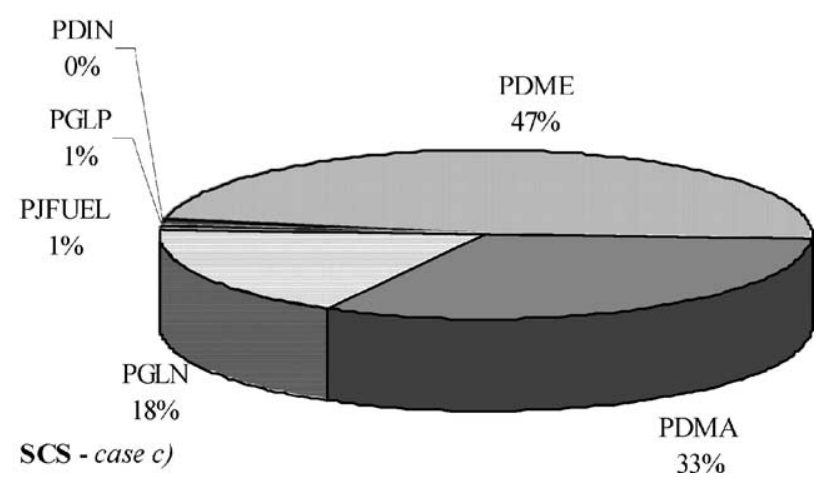

Fig. 23. Products feed flowrate percentage at terminal SCS.

VAP are then transferred to terminal SCS whereby transfer is accomplished to other terminals. Moreover, product distribution from the other refineries is significantly altered as seen by Figs. 22-25.

In terms of the objective function, case (a) presents net present value $0.5 \%$ higher than case (b) and $14 \%$ higher than case (c).

As a conclusion for case (b), pre-selection of some petroleum types tend to be counterbalanced by selection of other petroleum types absorbing the disturbing effect at the refinery level. A comparison of the petroleum type selections between case (a) and case (b) really reveals that there is a great difference in terms of number and amount of petroleum types selected. Such a measure avoids propagation of the disturbance over other facilities of the complex. As a conclusion for case (c), opposite to case (b), disturbance can only be absorbed by the whole distribution system. 

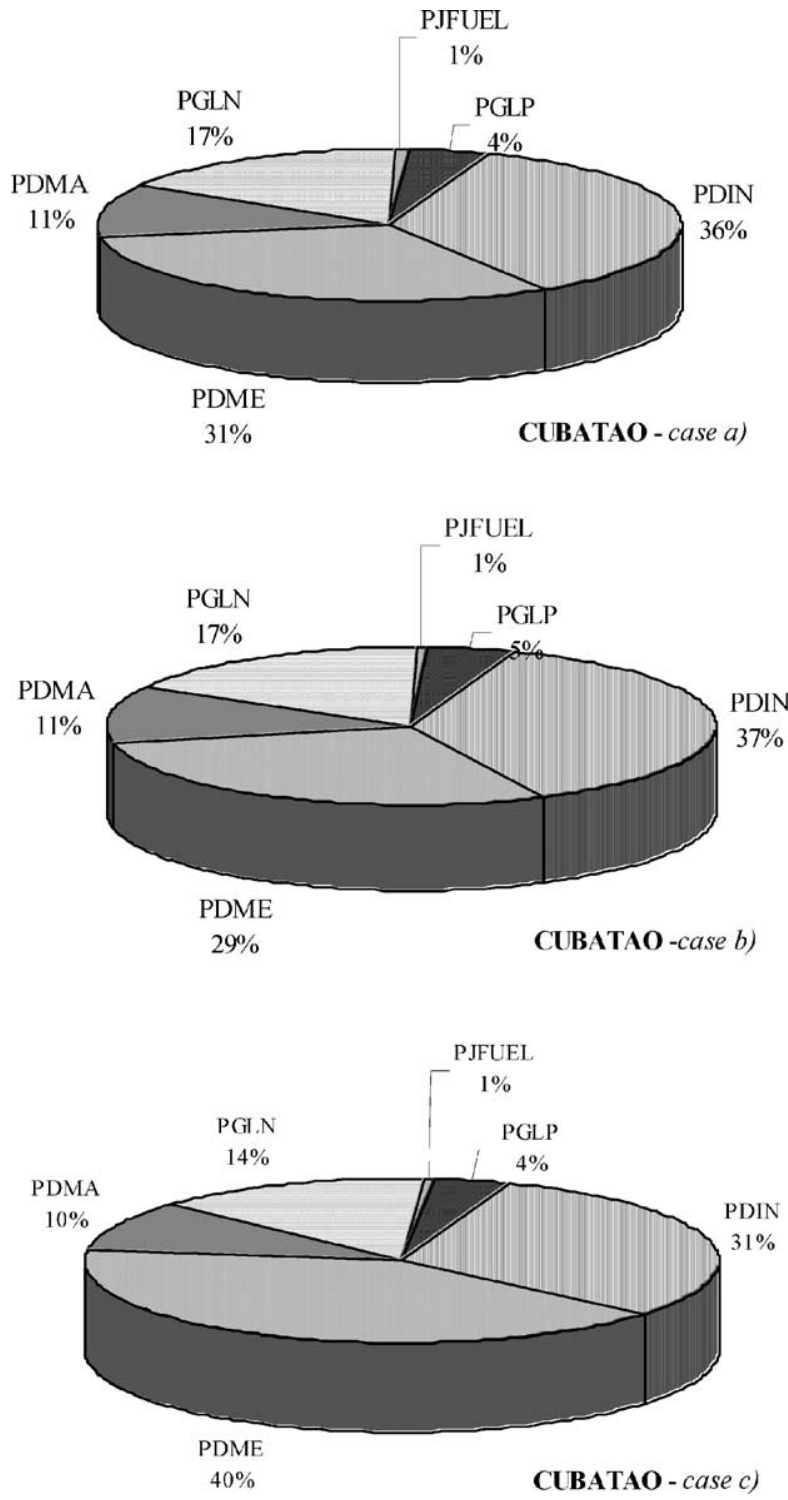

Fig. 24. Products feed flowrate percentage at terminal CUBATAO.

\section{Computational results}

Non-linearity in problem PSC appears in constraints (2), (4), (12), (14), (38) and (44)-(47) and also the objective function (18). Such equations represent process units or product tanks. Therefore, non-linearity is present only at refinery models. Although terminal models are basically rep-

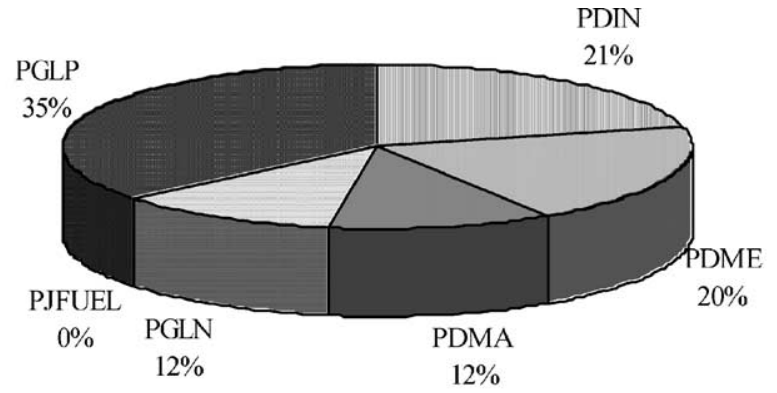

OSBRA - case a)

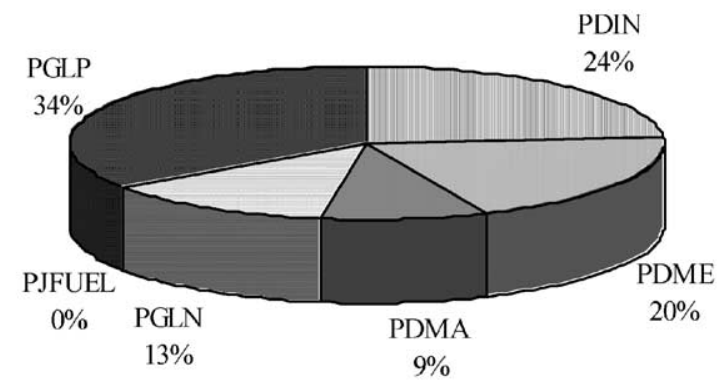

OSBRA - case b)

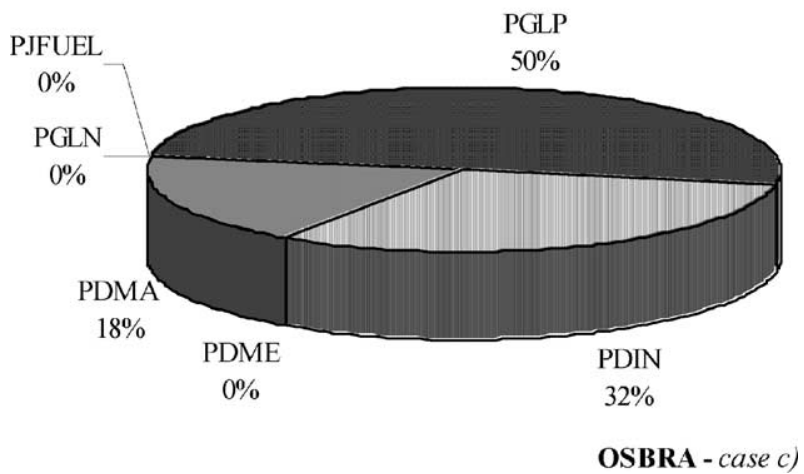

Fig. 25. Products feed flowrate percentage at terminal OSBRA.

resented by product tanks, Eq. (12) is not included in the set of constraints describing these tanks. Instead, product quality constraints are applied at refinery product tanks. Product properties must be within a range established by customer specifications and environmental regulations. Once all refineries are subjected to the same quality constraints, there is no need to recalculate properties at terminals, since

Table 5

Computational results

\begin{tabular}{|c|c|c|c|c|c|c|}
\hline & Case (a) & & Case (b) & & Case (c) & \\
\hline & Time period 1 & Time period 2 & Time period 1 & Time period 2 & Time period 1 & Time period 2 \\
\hline Constraints & 2304 & 4607 & 2306 & 4611 & 2304 & 4607 \\
\hline Variables & 2544 & 5087 & 2544 & 5087 & 2544 & 5087 \\
\hline Discrete variables & 195 & 390 & 195 & 390 & 195 & 390 \\
\hline Solution time (CPU s) & 116.8 & 656.2 & 152 & 915.6 & 157.8 & 2301.5 \\
\hline
\end{tabular}




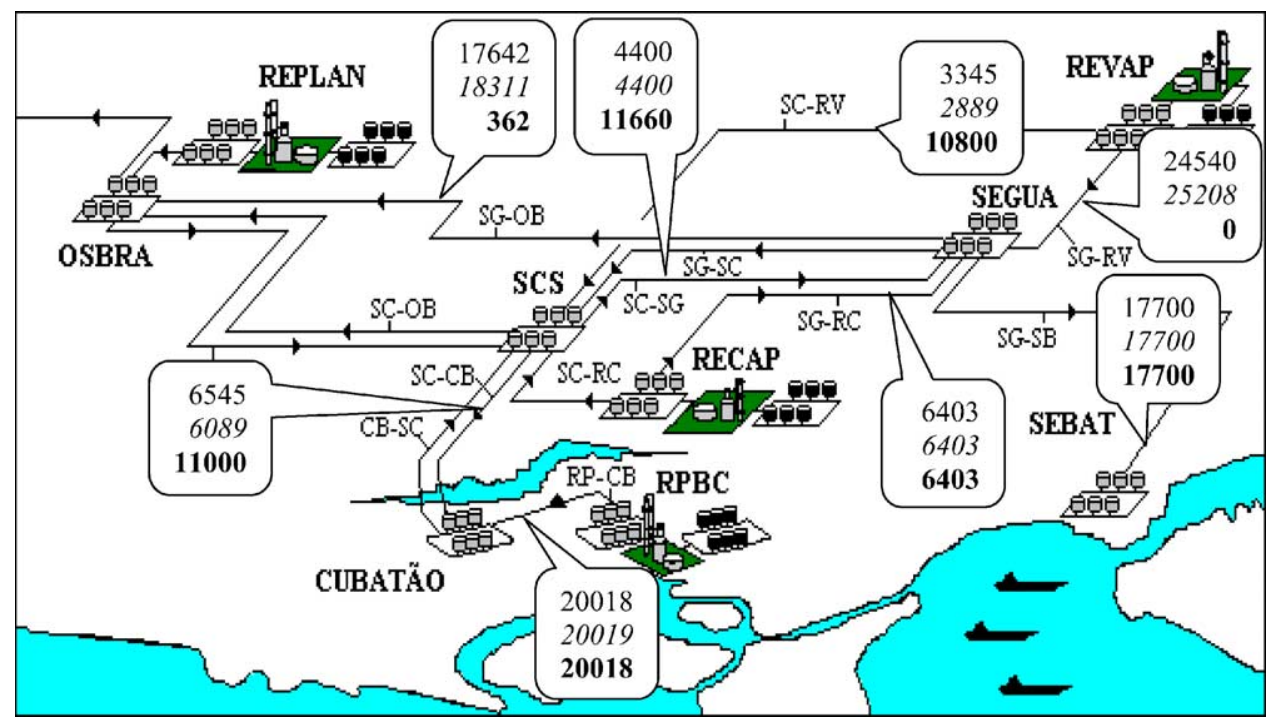

Fig. 26. Pipeline loads of the product distribution network.

mixture of streams of any product from any refinery will then always lie within property boundaries.

Table 5 presents computational results for the three cases considering a planning horizon of 1 and 2 time periods in order to verify the increase in model size as the planning horizon is extended and the corresponding difference in objective function value among the three cases. It can be observed, according to Table 5, that the number of constraints of problem PSC (case a) - original problem) doubles when time horizon is doubled, whereas solution time increases fourfold. Moreover, NLP subproblems consumed $97 \%$ of the solution time.

\section{Conclusions and future research}

In recent years, enterprises have been forced to change their management rules from a decentralized management to a context which share of information with other elements that compose the supply chain to which they belong has become vital. Model PSC presented in the present paper has demonstrated to be an efficient tool to assist production planning of a large petroleum supply chain. The whole complex topology is built through general structures representing processing units, storage tanks and pipelines and by connecting the elements of the chain according to the particularities of these structures. A small example showed how a refinery can be modeled based on the general structures. The representation of the targeted petroleum supply chain was then analyzed through three what-if cases and important characteristics of the system were discussed. The results have demonstrated the potential of problem PSC to real-world petroleum supply chains and how it can be used to help in the decision making process of the production planning. According to the presented results different strategies are adopted depend- ing on the locations and on the amplitude of the disturbance imposed on the petroleum supply chain. Moreover, it is illustrated the necessity of having a coordinated production planning in order to balance the dynamic behavior of the whole supply chain in face of different scenarios.

Since problem PSC presents a structure with localized non-linearity constraints, it might be profitable to employ any decomposition method that would result in smaller MINLP and MILP problems. Decomposition methods are now the main concern of the ongoing research, which would allow extension of time periods and inclusion of different scenarios.

\section{Acknowledgements}

The authors acknowledge financial support from FAPESP under Grant 00/02403-5 and 98/14.

\section{Appendix A}

Data for the supply chain case study Tables A.1-A.4.

Table A.1

Prices of petroleum types from all possible suppliers

\begin{tabular}{ll}
\hline Petroleum types & Cf $\left(\mathrm{US} \$ / \mathrm{m}^{3}\right)$ \\
\hline Lixo & 127 \\
Bonito & 132 \\
Larab & 139 \\
Marab & 136 \\
Marlin & 121 \\
RGN & 115 \\
Cabiun & 124
\end{tabular}


Table A.1 (Continued)

\begin{tabular}{ll}
\hline Petroleum types & Cf $\left(\mathrm{US} \$ / \mathrm{m}^{3}\right)$ \\
\hline Albaco & 117 \\
Bicudo & 123 \\
Condoso & 118 \\
Bonit & 127 \\
Bonny & 132 \\
Marli & 121 \\
RGNE & 121 \\
Cabiuna & 115 \\
Albacor & 124 \\
Brass & 115 \\
Palanca & 124 \\
Larabe & 118 \\
Coso & 127 \\
\hline
\end{tabular}

Table A.2

Inventory costs at every facility

\begin{tabular}{lll}
\hline Tank type & \multicolumn{2}{l}{ Cinv $\left(\mathrm{US} \$ \mathrm{~m}^{3} \mathrm{~d}\right)$} \\
\cline { 2 - 3 } & Petroleum & Product \\
\hline SEBAT & 0.11 & - \\
SEGUA & 0.23 & 0.35 \\
SCS & - & 0.28 \\
CUBATAO & 0.25 & 0.27 \\
OSBRA & - & 0.46 \\
REVAP & 0.12 & 0.32 \\
RPBC & 0.12 & 0.32 \\
RECAP & 0.12 & 0.32 \\
REPLAN & 0.12 & 0.32 \\
\hline
\end{tabular}

Table A.3

Transportation costs for petroleum and product pipelines

\begin{tabular}{llll}
\hline Petroleum pipeline & $\mathrm{Ct}\left(\mathrm{US} \$ \mathrm{~m}^{3}\right)$ & Product pipeline & $\mathrm{Ct}\left(\mathrm{US} \$ \mathrm{~m}^{3}\right)$ \\
\hline OBT-I & 0.044 & SG-SB & 0.098 \\
OBT-II & 0.044 & SG-RV & 0.031 \\
OVT-I & 0.052 & SG-SC & 0.037 \\
OVT-II & 0.038 & SG-OB & 0.024 \\
OVT-III & 0.045 & SG-RC & 0.036 \\
& & SC-RV & 0.051 \\
& & SC-RC & 0.085 \\
& SC-OB & 0.049 \\
& & SC-SG & 0.037 \\
& SC-CB & 0.042 \\
& & RP-CB & 0.034 \\
& & OB-SC & 0.032 \\
& & CB-SC & 0.042 \\
\hline
\end{tabular}

Table A.4

Product sale prices and demands for refineries, terminals and pipelines

\begin{tabular}{llrlll}
\hline Refinery & REVAP & & Refinery & \multicolumn{2}{l}{ RPBC } \\
\cline { 2 - 3 } & $\begin{array}{l}\text { Cp } \\
\left(\mathrm{US} \$ / \mathrm{m}^{3}\right)\end{array}$ & $\begin{array}{r}\text { Dem } \\
\left(\mathrm{m}^{3}\right)\end{array}$ & & $\begin{array}{l}\text { Cp } \\
\left(\mathrm{US} \$ / \mathrm{m}^{3}\right)\end{array}$ & $\begin{array}{c}\text { Dem } \\
\left(\mathrm{m}^{3}\right)\end{array}$ \\
\hline PC3 & 180 & 500 & PGLP & 118 & 200 \\
PC4 & 100 & 100 & PDIN & 230 & 350 \\
PMTBE & 100 & 0 & PDME & 242 & 500
\end{tabular}

Table A.4 (Continued)

\begin{tabular}{|c|c|c|c|c|c|c|}
\hline \multirow[t]{2}{*}{ Refinery } & \multicolumn{2}{|l|}{ REVAP } & \multirow[t]{2}{*}{ Refinery } & \multicolumn{3}{|l|}{$\mathrm{RPBC}$} \\
\hline & $\begin{array}{l}\text { Cp } \\
\left(\mathrm{US} \$ / \mathrm{m}^{3}\right)\end{array}$ & $\begin{array}{l}\text { Dem } \\
\left(\mathrm{m}^{3}\right)\end{array}$ & & $\begin{array}{l}\mathrm{Cp} \\
\left(\mathrm{US} \$ / \mathrm{m}^{3}\right)\end{array}$ & $\begin{array}{l}\text { Dem } \\
\left(\mathrm{m}^{3}\right)\end{array}$ & \\
\hline PGLP & 115 & 130 & PDMA & 212 & 300 & \\
\hline PJFUEL & 130 & 200 & PNAP & 146 & 900 & \\
\hline PPQN & 148 & 600 & PNAT & 160 & 158 & \\
\hline PGLN & 149 & 1000 & PPGC & 152 & 600 & \\
\hline PDIN & 210 & 500 & POC & 180 & 1500 & \\
\hline PDME & 230 & 600 & PDO & 159 & 700 & \\
\hline PDMA & 206 & 200 & PGLN & 270 & 500 & \\
\hline PFO1A & 139 & 800 & PGLA & 290 & 500 & \\
\hline PFO1B & 142 & 50 & PGLE & 298 & 200 & \\
\hline PFO4A & 151 & 4000 & PXIL & 160 & 100 & \\
\hline \multirow[t]{3}{*}{ PEXFO } & 146 & 300 & PTOL & 167 & 45 & \\
\hline & & & PBEN & 280 & 210 & \\
\hline & \multicolumn{2}{|l|}{ RECAP } & & \multicolumn{3}{|l|}{ REPLAN } \\
\hline PDIN & 132 & 0 & PNAL & 128 & 330 & \\
\hline PGLP & 65 & 200 & PNAP & 151 & 3850 & \\
\hline PRAT & 98 & 500 & PJFUEL & 175 & 100 & \\
\hline PGC & 202 & 400 & PDIL & 150 & 0 & \\
\hline POCP & 144 & 90 & PMTU & 180 & 200 & \\
\hline PLCO & 0 & 400 & PGLN & 181 & 2000 & \\
\hline PGLN & 141 & 150 & PGLP & 215 & 400 & \\
\hline PSOLB & 231 & 300 & PPGC & 122 & 230 & \\
\hline PDILT & 236 & 200 & PDIN & 280 & 2000 & \\
\hline \multirow[t]{6}{*}{ POCBV } & 257 & 90 & PDMA & 267 & 500 & \\
\hline & & & PDME & 254 & 6000 & \\
\hline & & & PFO1A & 160 & 1050 & \\
\hline & & & PFO1B & 162 & 1500 & \\
\hline & & & PFO4A & 158 & 2800 & \\
\hline & & & PEXFO & 149 & 990 & \\
\hline \multirow[t]{2}{*}{ Terminal } & \multicolumn{2}{|l|}{ SEBAT } & \multicolumn{2}{|l|}{ CUBATAO } & \multicolumn{2}{|l|}{ OSBRA } \\
\hline & $\begin{array}{l}\mathrm{Cp} \\
\left(\mathrm{US} \$ / \mathrm{m}^{3}\right) \\
\end{array}$ & $\begin{array}{l}\text { Dem } \\
\left(\mathrm{m}^{3}\right)\end{array}$ & $\begin{array}{l}\mathrm{Cp} \\
\left(\mathrm{US} \$ / \mathrm{m}^{3}\right)\end{array}$ & $\begin{array}{l}\text { Dem } \\
\left(\mathrm{m}^{3}\right)\end{array}$ & $\begin{array}{l}\mathrm{Cp} \\
\left(\mathrm{US} \$ / \mathrm{m}^{3}\right)\end{array}$ & $\begin{array}{l}\text { Dem } \\
\left(\mathrm{m}^{3}\right)\end{array}$ \\
\hline PDIN & 230 & 3000 & 230 & 4000 & 230 & 10500 \\
\hline PDME & 242 & 4400 & 242 & 3000 & 242 & 5500 \\
\hline PDMA & 226 & 3000 & 226 & 2000 & 226 & 5400 \\
\hline PGLN & 270 & 6500 & 270 & 600 & 270 & 1000 \\
\hline PJFUEL & 175 & 0 & 175 & 200 & 175 & 500 \\
\hline PGLP & 128 & 800 & 128 & 800 & 128 & 3600 \\
\hline
\end{tabular}

\section{References}

Barnes, R., Linke, P. \& Kokossis, A. (2002). Optimization of oil field development production capacity. In ESCAPE 12 proceedings (pp. 631-636). The Hague, the Netherlands.

Beamon, B. M. (1998). Supply chain design and analysis: models and methods. International Journal on Production Economics, 55, 281294.

Bok, J. K., Lee, H., \& Park, S. (1998). Robust investment model for long-range capacity expansion of chemical processing networks under uncertain demand forecast scenarios. Computers and Chemical Engineering, 22(7-8), 1037-1049

Bok, J. K., Grossmann, I. E., \& Park, S. (2000). Supply chain optimization in continuous flexible processes. Industrial and Engineering Chemistry Research, 39, 1279-1290.

Brooke, A., Kendrick, D. \& Meeraus, A. (1998). GAMS: a user's guide. San Francisco, CA: The Scientific Press.

Cheng, L. \& Duran, M. (2003). World-wide crude transportation logistics: a decision support system based on simulation and optimization. In 
I. E. Grossmann \& C. M. McDonald (Eds.), Proceedings of fourth international conference on foundations of computer-aided process operations (pp. 273-280). Coral Springs, CAChE.

Dempster, M. A. H., Pedron, N. H., Medova, E. A., Scott, J. E., \& Sembos, A. (2000). Planning logistics operations in the oil industry. Journal of Operational Research Society, 51(11), 1271-1288.

Drud, A. S. (1994). CONOPT: a large scale GRG code. ORSA Journal of Computing, 6, 207-216.

Escudero, L. F., Quintana, F. J., \& Salmeron, J. (1999). CORO, a modeling and an algorithmic framework for oil supply, transformation and distribution optimization under uncertainty. European Journal of Operational Research, 114(3), 638-656.

Feord, D., Jakeman, C. \& Shah, N. (2002) Modeling multi-site production to optimize customer orders. In ESCAPE 12 proceedings (pp. 661-666). The Hague, the Netherlands.

Forrest, J. \& Oettli, M. (2003). Rigorous simulation supports accurate refinery decisions. In I. E. Grossmann \& C. M. McDonald (Eds.), Proceedings of fourth international conference on foundations of computers-aided process operations (pp. 273-280), Coral Springs, CAChE.

Iakovou, E. T. (2001). An interactive multiobjective model for the strategic transportation of petroleum products: risk analysis and routing. Safety Science, 39, 19-29.

IBM (1991). OSL, guide and reference (release 2). Kingston, NY: IBM.

Ierapetritou, M. G., Floudas, C. A., Vasantharajan, S., \& Cullick, A. S. (1999). Optimal location of vertical wells: decomposition approach. AIChE Journal, 45(4), 844-859.

Iyer, R. R., Grossmann, I. E., Vasantharajan, S., \& Cullick, A. S. (1998). Optimal planning and scheduling of offshore oil field infrastructure investment and operations. Industrial and Engineering Chemistry Research, 37, 1380-1397.

Jia, Z. \& Ierapetritou, M. (2003). Efficient short-term scheduling of refinery operations based on a continuous time formulation. In I. E. Grossmann \& C. M. McDonald (Eds.), Proceedings of fourth international conference on foundations of computer-aided process operations (pp. 327-330), Coral Springs, CAChE.

Kosmidis, V. D., Perkins, J. D., Pistikopoulos, E. N. (2002). A mixed integer optimization strategy for integrated gas/oil production. In $E S$ CAPE 12 proceedings (pp. 697-702), The Hague, the Netherlands.

Lamming, R. (1996). Squaring lean supply chain management. International Journal of Operation and Production Management, 16(2), 183-196.

Lasschuit, W. \& Thijssen, N. (2003). Supporting supply chain planning and scheduling decisions in the oil \& chemical industry. In I. E. Grossmann \& C. M. McDonald (Eds.), Proceedings of fourth international conference on foundations of computer-aided process operations (pp. 37-44), Coral Springs, CAChE.

Lee, H., Pinto, J. M., Grossmann, I. E., \& Park, S. (1996). Mixed-integer linear programming model for refinery short-term scheduling of crude oil unloading with inventory management. Industrial and Engineering Chemistry Research, 35(5), 1630-1641.

Liu, M. L., \& Sahinidis, N. V. (1997). Process planning in a fuzzy environment. European Journal of Operational Research, 100, 142169.

Magalhães, M.V. \& Shah, N. (2003). Crude oil scheduling. In I. E. Grossmann \& C. M. McDonald (Eds.), Proceedings of fourth international conference on foundations of computer-aided process operations (pp. 323-326), Coral Springs, CAChE, 323-326.

Magatão, L., Arruda, L. V. R., Neves-Jr, F. (2002). A mixed integer programming approach for scheduling commodities in a pipeline. In ESCAPE 12 proceedings (pp. 715-720), The Hague, the Netherlands.

Más, R., \& Pinto, J. M. (2003). A Mixed-Integer Optimization Strategy for Oil Supply in Distribution Complexes. Optimization and Engineering, 4, 23-64.

Perea, E., Grossmann, I. E., Ydstie, B. E., \& Tahmassebi, T. (2000). Dynamic modeling and classical control theory for supply chain management. Computers and Chemical Engineering, 24, 11431149.

Perea-López, E., Grossmann, I. E., \& Ydstie, B. E. (2001). Dynamic modeling and decentralized control of supply chains. Industrial and Engineering Chemistry Research, 40, 3369-3383.

Pinto, J. M., \& Moro, L. F. L. (2000). A planning model for petroleum refineries. Brazilian Journal of Chemical Engineering, 17(4-7), 575585.

Pinto, J. M., Joly, M., \& Moro, L. F. L. (2000). Planning and scheduling models for refinery operations. Computers and Chemical Engineering, 24, 2259-2276.

Ponnambalam, K., Vannelli, A., \& Woo, S. (1992). An interior point method implementation for solving large planning problems in the oil refinery industry. Canadian Journal of Chemical Engineering, 70(2), 368-374.

Ross, A. D. (2000). Performance-based strategic resource allocation in supply networks. International Journal of Production Economics, 63, 255-266.

Sear, T. N. (1993). Logistics planning in the downstream oil industry. Journal of Operational Research Society, 44(1), 9-17.

Song, J., Bok, J. K., Park, H. \& Park, S. (2002). Supply chain optimization involving long-term decision-making. ESCAPE 12 proceedings (pp. 799-804). The Hague, the Netherlands.

Stebel, S. L., Arruda, L. V. R., Fabro, J. A., Rodrigues L.C.A. (2002). Modeling liquefied petroleum gas storage and distribution. ESCAPE 12 proceedings (pp. 805-810). The Hague, the Netherlands.

Tan, K. C. (2001). A framework of supply chain management literature. European Journal of Purchasing and Supply Management, 7, 3948 .

Thomas, D. J., \& Griffin, P. M. (1996). Coordinated supply chain management. European Journal of Operational Research, 94, 1-15.

Türkay, M., \& Grossmann, I. E. (1996). Logic-based MINLP algorithms for the optimal synthesis of process networks. Computers and Chemical Engineering, 20, 959-978.

Van den Heever, S. A., \& Grossmann, I. E. (1999). Disjunctive multiperiod optimization methods for design and planning of chemical process systems. Computers and Chemical Engineering, 23, 1075-1095.

Van den Heever, S. A., \& Grossmann, I. E. (2000). An iterative aggregation/disaggregation approach for the solution of a mixed-integer nonlinear oilfield infrastructure planning model. Industrial and Engineering Chemistry Research, 39, 1955-1971.

Van den Heever, S., Grossmann, I. E., Vasantharajan, S., \& Edwards, K. (2000). Integrating complex economic objectives with the design and planning of offshore oilfield infrastructure. Computers and Chemical Engineering, 24, 1049-1055.

Vecchietti, A., \& Grossmann, I. E. (2000). Modeling issues and implementation of language for disjunctive programming. Computers and Chemical Engineering, 24, 2143-2155.

Vidal, C. J., \& Goetschalckx, M. (1997). Strategic production-distribution models: a critical review with emphasis on global supply chain models. European Journal of Operational Research, 98, 1-18.

Viswanathan, J., \& Grossmann, I. E. (1990). A combined penalty function and outer-approximation method for MINLP optimization. Computers and Chemical Engineering, 14, 769.

Wenkai, L. \& Hui, C. W. (2003). Plant-wide scheduling and marginal value analysis for a refinery. In I. E. Grossmann \& C. M. McDonald (Eds.), Proceedings of fourth international conference on foundations of computer-aided process operations (pp. 339-342). Coral Springs, CAChE.

Ydstie, B. E., Coffey, D. \& Read, M. (2003). Control and optimization of supply networks. In: I. E. Grossmann, C. M. McDonald (Eds.), Proceedings of fourth international conference on foundations of computer-aided process operations (pp. 167-185). Coral Springs, CAChE.

Zhuo, Z., Cheng, S., \& Hua, B. (2000). Supply chain optimization of continuous process industries with sustainability considerations. Computers and Chemical Engineering, 24, 1151-1158. 